\title{
Identification of key modules and hub genes regulating drought stress response in rice drought sensitive line PY6 by weighted gene co-expression network analysis
}

\author{
Baiyang Yu \\ Guangxi University \\ Jianbin Liu \\ Guangxi University \\ Di Wu \\ Guangxi University \\ Ying Liu \\ Guangxi University
}

\section{Weijian Cen}

Guangxi University

\section{Shaokui Wang}

South china Agricultural University

Rongbai Li

Guangxi University

Jijing Luo ( $\nabla_{\text {jjluo@gxu.edu.cn ) }}$

Guangxi University https://orcid.org/0000-0001-5664-0881

\section{Original article}

Keywords: Rice, Drought stress, QTL locus, Transcriptional profiling, Drought sensitive phenotype,

Transcriptome

Posted Date: June 8th, 2020

DOI: https://doi.org/10.21203/rs.3.rs-33321/v1

License: (c) (i) This work is licensed under a Creative Commons Attribution 4.0 International License.

Read Full License 


\section{Abstract}

Background: Drought stress is an adverse factor with deleterious effects on several facets of rice growth. However, the mechanism underlying drought resistance in rice remains unclear. In order to genetically understand the potential molecular mechanism for drought response in rice, a drought sensitive Chromosome Segment Substitution Line (CSSL) PY6, which was constructed by the introgression of genomic segments of drought sensitive variety LAMBAYEQUE1 into drought-resistance variety PR403 via backcrossing, was used to map the QTL locus dss-1 for its sensitive phenotype, and to reveal the impact of dss-1 on the transcriptional profiling of PY6 via RNA-seq and WGCNA (weighted gene co-expression network analysis) analysis.

Results: The genetic linkage analysis showed that dss-1 was located on the short arm of chromosome 1 of rice. In contrast to PR403, the over-accumulation of $\mathrm{H} 2 \mathrm{O} 2$ and MDA that might result in drought sensitive phenotype was observed in PY6 under drought stress. In the analysis of RNA-seq data, the identified differentially expressed genes (DEGs) mainly enriched in photosynthesis-related GO terms and exhibited a down-regulation pattern of their expressions in both PY6 and PR403 in response to drought stress, indicating that the photosynthesis was greatly inhibited in rice. Further WGCNA analysis constructed a co-expression network with 26 gene modules in which 4 and 3 modules that were highly correlated with $\mathrm{H} 2 \mathrm{O} 2$ and MDA, respectively. Likewise, the $\mathrm{GO}$ analysis of the differentially expressed hub genes (DEHGs) enriched in $\mathrm{H} 2 \mathrm{O} 2$-correlated modules showed that the photosynthesis related $\mathrm{GO}$ terms were consistently over-represented. Furthermore, functional annotation of DEHGs in $\mathrm{H} 2 \mathrm{O} 2$ and MDA correlated modules revealed a cross talk between abiotic and biotic stresses. This was reflected by the differential expression alterations of hub genes which were annotated as encoding MYBs, laccases, WRKYs, and PRs family proteins, and ZFP36 were notably observed between PY6 and PR403 in response drought stress.

Conclusions: Collectively, we speculated that drought-induced the inhibition of photosynthesis lead to the accumulation of $\mathrm{H} 2 \mathrm{O} 2$ and MDA that can trigger the reprogramming the profiling of transcriptome in rice. This included the differential regulation of hub genes that involve in ROS eliminated pathways to prevent the damage of rice plants from oxidative stress.

\section{Background}

Abiotic stresses, such as drought, chilling, heat, and salinity, etc., are wide-spread factors with deleterious effects on several facets of plant life. However, as sessile organisms, higher plants usually adopt the 'overcome' strategy upon encountering any extreme environmental stresses, in contrast to animals, which preferentially opt for the tolerance or avoidance of unfavorable circumstances. In general, various tolerance/avoidance mechanisms (de Zelicourt et al. 2016), such as the regulation of endogenous hormone signaling(Verma et al. 2016), the increase of wax deposition in cuticle (Zhu and Xiong 2013), and the modulation of stomatal state (Huber et al. 2019), are employed in response to abiotic stresses. 
Rice (Oryza sativa L.) is a staple food crop of the world. Drought is one of major abiotic constraints for rice production with the increasing of the global water shortage. Two important strategies, dehydration tolerance and avoidance, are adopted in plants to cope with drought stress. Dehydration avoidance depends on the development of a larger and deeper root system to uptake water from soil and reducing water loss via the modulation of stomatal opening. Dehydration tolerance mainly enhances drought resistance by the complex mechanisms in later stage of drought stress such as anti-oxidation processes, ABA signaling transduction, osmotic adjustment, and cell membrane protection (Hu and Xiong 2014; Luo 2010).

Several QTLs for dehydration tolerance and avoidance in rice were cloned via map-based cloning. Moreover, a large number of QTLs for root growth(Lou et al. 2015), osmotic pressure regulation (Lilley et al. 1996), ROS regulation, and cuticular wax accumulation which may contribute to enhance drought resistance were mapped to different locations of rice genome (Huang et al. 2019; Huang et al. 2009). $D R O 1$, one of the gene that has been well-characterized, involves in the regulation of rice root development under drought stress. DRO1 regulates cell elongation in the root tip that causes downward bending of the root to avoid water deficit by increasing deep rooting (Uga et al. 2013). DST was identified as negative regulator of $\mathrm{H}_{2} \mathrm{O}_{2}$ accumulation in guard cell that functions in the modulation of stomatal opening. Loss function of DST increases stomatal closure, resulting in enhanced drought tolerance in rice (Huang et al. 2009). In addition, DS8 participates in the synthesis of plant cuticular wax and in the regulation of stomatal movement in response to drought stress (Huang et al. 2019). The studies of these genes indicated that intricate mechanisms are adopted in rice plants for the adaption of drought stress.

Although the over-accumulation of reactive oxygen species (ROS), including singlet oxygen, $\mathrm{H}_{2} \mathrm{O}_{2}$, and superoxide anion, causes severe injuries to plant cells, even leading to programed cell death (Liu et al. 2016), the generation of ROS acts as second messenger that involves in the stress signaling response, photosynthetic regulation, stomatal movement, and the development of higher plants. ROS homeostasis plays a key role in plant drought resistance regulation (Ramachandra Reddy et al. 2004; Wang et al. 2016). Plants have evolved a series of enzymatic and nonenzymatic antioxidant systems. Enzymatic system, including superoxide dismutase (SOD), catalase (CAT), and ascorbate peroxidase (APX), participates in scavenging ROS and preventing the damage from oxidative stress ( $X u$ et al. 2008). SODs function in the dismutation of $\mathrm{O}^{2-}$ to $\mathrm{H}_{2} \mathrm{O}_{2}$ and $\mathrm{O}_{2}$; then the resultant $\mathrm{H}_{2} \mathrm{O}_{2}$ was catalyzed into $\mathrm{H}_{2} \mathrm{O}$ and $\mathrm{O}_{2}$ by the effect of CAT and APX (Mori and Schroeder 2004). Chloroplasts is an organelle for photosynthesis in plant cells. As a key process for the responsive regulation, when rice plants are subjected to abiotic stresses, photosynthetic activity is greatly inhibited (Cen et al. 2018). The inhibition of photosynthesis reduces the utilization of absorbed light energy, resulting in the generation of ROS in chloroplasts, which in turn causes the photodamage to photosystem proteins, such as D1, a core component of photosystem II (Kojima et al. 2007). Recently, the emerging evidence indicated the high correlation among antioxidant mechanism, photosynthesis regulation, and drought-tolerance (Gan et al. 2019; Ramachandra Reddy et al. 2004; Zong et al. 2016). In addition, $A B A$ induces the accumulation of $\mathrm{H}_{2} \mathrm{O}_{2}$ via the activation of NADPH oxidase, which is activated by SnRK2s phosphorylation, and thereby, resulting in the stomatal 
closure eventually. Moreover, the accumulation of $A B A$ induces the expression of $C A T$, suggesting that a certain relationship existed between ABA signaling and $\mathrm{H}_{2} \mathrm{O}_{2}$ tuning (Bailey-Serres et al. 2019; Liu et al. 2014; Okamoto et al. 2013; Shim et al. 2018; Tang et al. 2016; Wang et al. 2018).

Recent reports have suggested that WRKY transcription factors (TFs) participate in the regulatory mechanism pathways of abiotic stresses, including drought and salinity (Xiao et al. 2013; Yokotani et al. 2013). WRKY TFs are plant specific group of zinc finger transcription factors that are characteristic of containing a conserved WRKY domain, and bind to a consensus cis-element W-box (TTGACT/C) (Ross et al. 2007). The majority of over 100 members of which in rice involve in the plant defense response in either a negative or positive manner (Group 2012; Ross et al. 2007). Some WRKY members have important roles in abiotic stress responses, for example OsWRKY13 was suggested to regulate the antagonistic cross talk between drought and disease resistance pathways via the repression of SNAC1 and WRKY45-1 (Xiao et al. 2013; Yokotani et al. 2013). Meanwhile, pathogenesis-related (PR) proteins have been well defined as a group of proteins that are induced not only by pathogen infection such as viruses, bacteria, and fungi, but also in response to abiotic stresses, including drought and salinity (Takeuchi et al. 2011). All the PR proteins in both monocot and dicotyledon were classified into 17 families (Liu and Ekramoddoullah 2006). Among of which, PR3 and PR4 have plant chitinase activity; PR5 family of proteins includes permatins, osmotins, zeanatins, and thaumatin-like proteins (Agarwal and Agarwal 2014). Besides, the PR10 genes are belonged to a multigene family in various plants, and exert RNase activity, ligand binding, post-translational modification (phosphorylation), and phytohormone signaling in stress responses. The promoters of PR10 genes harbor cis-acting elements for WRKY, bZIP, ERF, MYB transcription factors, suggesting the pivotal roles of PR10 play in the stress response pathways (Agarwal and Agarwal 2014).

With the rapid development of next generation deep resequencing technology, RNA-seq is widely used to explorer the transcriptomic profiling of plants in response to the challenges of adverse environments. Recent studies revealed that antioxidant process, ABA pathway, and photosynthesis were the target biological processes for plants in response to environmental change at transcription level (Varoquaux et al. 2019; Zhang et al. 2016). More intriguingly, photosynthesis rate was found to be declined under drought stress, especially in drought sensitive genotype, suggesting that the enhancement of antioxidant capacity was in favor of maintaining higher photosynthetic activity, and thereby would improve drought resistance of plants (Zhang et al. 2016). Moreover, phytohormone signaling and $\mathrm{Ca}^{2+}$ signaling were also highlighted in transcript profiling and revealed the cross-talk among phytohormone signaling pathways (Kim et al. 2018; LY et al. 2014). In addition, a large number of transcription factor families, like WRKY, bZIP, and MYB, were identified involved in ABA-mediated signaling transduction under abiotic stresses (Borah et al. 2017; Okay et al. 2014). However, the molecular mechanism of drought tolerance/sensitive still need to be further investigation.

Weighted gene co-expression network analysis (WGCNA) is a new algorithm that is used to identify the potential gene modules with highest connectivity among genes and is correlated to certain phenotypes in the gene expression data (Langfelder and Horvath 2008; Zhang and Horvath 2005). WGCNA constructs a 
co-expression network that can indicate the correlations among genes across samples. Based on the coexpressed relationships, genes with similar expression are grouped into the same module, thus suggesting that the genes in the same module may have similar function or possibly have common biological regulatory roles (Zhou et al. 2018). The method has been successfully applied in numerous study cases which were used to identify hub genes and the relationship between gene expression data and relevant phenotypes (Clarke et al. 2013; Deng et al. 2019; Du et al. 2017; Greenham et al. 2017; Shaik and Ramakrishna 2013; Zhang et al. 2018).

Here, we identified a drought sensitive rice chromosome single substitution segment line (CSSL) PY6, which carries the substitution segment derived from a drought sensitive variety LAMBAYEQUE1 by backcrossing into drought tolerance variety PR403 background. A locus $d s s-1$ underlying drought sensitive phenotype of PY6 was harbored in the short arm of chromosome 1. In order to investigate the impact of $d s s-1$ on the transcriptional profiling of PY6, RNA-seq was performed to identify differential expression genes (DEGs) under drought stress treatment. Further, WGCNA was applied to identify hub genes from the modules which were highly correlated with drought-induced physiological indicators. By this approach, we aimed to infer $d s s-1$ mediated potential regulatory network that are relevant to the drought stress tolerance in rice.

\section{Results}

\section{Identification of $d s s-1$ locus for drought sensitive phenotype in the CSSLS}

In our previous study, a set of rice CSSLs with 140 lines was constructed by the introgression of the genomic segments of drought sensitive variety LAMBAYEQUE1 into the genome of drought resistant variety PR403 through backcross (Fig. 1A). The overlapped introgressed segments defined by 167 molecular markers covered the whole genome of LAMBAYEQUE1 (unpublished data). In order to uncover the molecular regulatory mechanism underlying the drought sensitive phenotype in LAMBAYEQUE1, drought stress treatment was performed to identify the major QTL (s) for drought sensitive trait. PY6, one of the CSSLs, was highlighted for its drought sensitive phenotype. After 10-day drought treatment, the treated CSSLs were re-watered and allowed to recover for 3 days. In the screening, PY6, one of CSSLs, was identified with the significant difference of survival rate $(20.0 \%)$ by comparing with its recurrent parent PR403 (93.3\%), whereas no significant difference was observed in the survival rate of PY6 and its donor parent LAMBAYEQUE1 (Fig. 1B-C). During the drought stress treatment, the relative water content of the seedlings was declined in PY6 and PR403 with the decreasing of the soil moisture. However, starting from $120 \mathrm{~h}$, the significant difference was observed between PY6 and PR403 and the former one exhibited more severe dehydration at the later stage of the treatment, suggesting the drought stress broke the balance of water uptake and evaporation in PY6 (Fig. 1D). PY6 carries a 10-Mb chromosome segment derived from LAMBAYEQUE1 on the short arm of chromosome 1. These results suggested that the segment from LAMBAYEQUE1 might harbor a major QTL locus for the drought sensitive phenotype of PY6. We designated it as $d s s-1$. 
To reveal the genetic basis underlying the drought sensitive phenotype conferred by $d s s-1$ locus, PY 6 was backcrossed with recurrent parent PR403 to construct mapping population. The F1 plants exhibited drought resistance, similar to that of parental line, PR403. Then, F2 population was developed to determine the inheritance feature of $d s s-1$. In a 151-individual F2 population, 111 showed drought resistance and 40 showed drought sensitive traits (resistant: sensitive $\approx 3: 1, \chi^{2}=0.1788<\chi^{2}{ }_{0.05}=3.84$ ), indicating that drought sensitive trait is controlled by a single recessive gene. In turn, the recombinants were screened for genetic linkage analysis, and dss-1 was finally narrowed down to 4.01-Mb interval (Fig. $1 \mathrm{E})$. To further confirm the reliability of $d s s-1$ mapping, GWAS was performed based on 84 rice varieties that were selected from 3000 Rice Genomes Project (Wang et al. 2018). Drought stress phenotype was investigated under 20\% PEG-6000 treatment. Using the general mixed linear model, two SNP located on the region of $d s s-1$ interval were detected associated with drought stress phenotype (Fig. 1E). Ten candidate genes for $d s s-1$ were identified in the vicinity around 200-kb of associated SNPs (Table S2).

\section{Drought induced $\mathrm{H}_{2} \mathrm{O}_{2}$ and MDA accumulation the leaves of PY6}

Given that the previous reports indicated that drought stress was known to inhibit photosynthetic activity plants due to an imbalance between light capture and its utilization (FOYER and NOCTOR 2000), and coupled with considerable potential for increased accumulation of superoxide and hydrogen peroxide in chloroplasts (Robinson and Bunce 2000), we examined the accumulation of ROS and the activity of its scavenging enzymes in the leaves of drought-treated PY6. Leaf samples were harvested at 4 sampling points (Fig. S1). In contrast to PR403, the increasing accumulation of $\mathrm{H}_{2} \mathrm{O}_{2}$ was detected in PY6 from points 40 to 15, whereas the enhanced content only can be observed at point 22 in PR403, thereby the significantly increased accumulation of $\mathrm{H}_{2} \mathrm{O}_{2}$ was detected in $\mathrm{PY} 6$ at sampling points 22 and 15 by comparing with their respective controls (Fig. 2A). The remarkable accumulation of $\mathrm{H}_{2} \mathrm{O}_{2}$ in the leaves of PY6 was confirmed by DAB staining (Fig. 2D). Consistently, the activities of POD and CAT were upregulated in response to the accumulation of $\mathrm{H}_{2} \mathrm{O}_{2}$ (Fig. 2B, C). However, the activity of APX, a major $\mathrm{H}_{2} \mathrm{O}_{2}$-scevenging enzyme that removes $\mathrm{H}_{2} \mathrm{O}_{2}$ via the ascorbate-glutathione cycle, was not induced and no significant difference was observed between both genotypes during drought treatment (Fig. S2A). For the dynamic changes of superoxide, the content of SOA (superoxide anion) and the activity of its scavenging enzyme SOD at point 15 were exhibited significant difference between two genotypes with higher values in PY6. However, the content of SOA in whole period of drought treatment was not significantly induced in contrast to the untreated control (point 40) (Fig. 2E, F; Fig. S2B). Moreover, the contents of MDA, a major reactive aldehyde resulting from the peroxidation of polyunsaturated fatty acid (PUFA) constituents of biological membranes and acting as the indicator of the abiotic stress-induced bio-membrane damage, were shown significantly accumulated in PY6 by comparing with those in PR403 at points 22 and 15, respectively (Fig. 2G). 
Taken all these together, our results suggested that the drought sensitive phenotype might be caused by the over-accumulation of ROS, especially $\mathrm{H}_{2} \mathrm{O}_{2}$ that could result in the severe damage to the plant cells and the peroxidation of cell membrane, and thereby leading to the dehydration of rice plants under drought stress.

\section{The accumulation of $\mathrm{ABA}$ and stomatal modulation during drought stress treatment}

As above mentioned, PY6 exhibited more severe dehydration at the later stage of the treatment, suggesting that PY 6 either had a higher water transpiration or lower water uptake ability when it was subjected to drought stress. ABA is a key regulator for plant stress responses and regulates a series of physiological processes, including tolerance to abiotic stresses and stomatal closure (Sah et al. 2016). In order to determine the role of ABA-mediated stomatal movement played in the drought-induced severe dehydration in PY6, the content of $A B A$ and the status of stomatal apertures in drought treated samples were examined. The content of ABA was accumulated during drought stress treatment, although no significant difference between PY6 and PR403 was observed at any sampling point (Fig. S2C). Scanning electron microscopy was used to examine the stomata status of leaf samples. By comparison with the untreated control, the percentage of completely closed stomata in the drought-treated samples was significantly elevated. However, PY6 and PR403 have similar patterns in modulating their stomata in response to drought stress, and also no significant difference in the stomatal density was observed in both genotypes (Fig. S2D). Therefore, these results suggested that severe dehydration in drought-treated PY6 might not result from the defect of ABA-mediated stomatal transpiration regulation, but cause by the limitation of water uptake or by other water loss pathway.

\section{Comparative transcriptional profiling of PY6 under drought stress}

To further unveil the impact of $d s s-1$ on drought stress-induced $\mathrm{H}_{2} \mathrm{O}_{2}$ accumulation that might lead to the drought sensitive of PY6, we investigated the transcriptional profiling of PY6 and PR403 in response to drought stress through RNA-Seq. Principal components analysis (PCA) was initially performed based on all the transcriptional profiling data to detect the variations among the samples with the imposition of the drought treatment (Fig. 3A). PC1 explained 37.98\% of total variation. The samples of CK40 and CK22/20 of both PY6 and PR403 were clearly separated by PC1, indicating the effect of the development imposed on the variations, while PC1 also separated drought-treated samples of points 22 from 20, indicating the effect of imposition of drought treatment on the transcriptomes of the samples. PC2 explained $27.94 \%$ of total variation and clearly separated drought-treated samples from the parallel untreated samples (Fig. 3A). Moreover, both PY6 and PR403 samples of point 20 exhibited the remarkable divergence from other sampling points, indicating the dramatic transcriptomic reprogramming occurred at this sampling point. 
Drought-induced DEGs were identified by comparing with untreated controls (Table S3). It was worth noting that the development-dependent DEGs were detected in the same sampling points of well-watered samples with the same criterion and they were excluded from the DEGs set to avoid the misleading to understand drought-induced transcriptomic responses (Table S3-5 -12). Finally, in the two sampling points of PR403, 3052 DEGs including 1135 up-regulated and 1917 down-regulated were detected at point 22 (Table S3-1), while 5821 DEGs were detected at point 20, including 2383 up-regulated and 3438 down-regulated DEGs (Table S3-2). In PY6, 3145 (1748 up-regulated/1397 down-regulated) and 5529 (2655 up-regulated/2874 down-regulated) were detected at point 22 and 20, respectively (Table 1; Table S3-3, -4). Among the resultant DEGs, venn diagram analysis showed that 1142 DEGs were common between PR403 and PY6 at point 22, while 3184 were common between PR403 and PY6 at point 20, which accounted for $38.4 \%$ and $48.7 \%$ of total DEGs in both sampling points, respectively (Fig. 3B-C, Table 1), demonstrating that PY6 has a similar genetic background and a similar drought stress response to those of PR403 from another side.

To verify the data quality of RNA-seq, five genes was selected for qRT-PCR. Similar trends of expression changes were observed between qRT-PCR and RNA-seq, indicating that transcriptomic data are reliable for further analysis (Fig. S3A-E, Table S1).

\section{Gene ontology enrichment analysis}

GO enrichment analysis was performed to enrich the DEGs into the functional categories of biological processes (BP), cellular components (CC), and molecular function (MF) subgroup. The results showed that all the DEGs were enriched into the $\mathrm{GO}$ terms that were related to photosynthesis in chloroplasts (Fig. 4A-D). For instance, in terms of BP group, the GO terms including photosynthesis (GO: G0:0015979), photosynthesis, light harvesting (G0:0009765), photosynthesis, light harvesting in photosystem I (GO:0009768), photosynthesis, light reaction (G0:0019684), chlorophyll biosynthetic process (G0:0015995), and porphyrin-containing compound biosynthetic process (G0:0006779), were highly significantly over-represented. The over-represented GO terms, such as chloroplast part (G0:0044434), chloroplast envelope (G0:0009941), chloroplast thylakoid (GO:0009534), chloroplast thylakoid membrane (G0:0009535), chloroplast thylakoid lumen (G0:0009543) in CC (Fig. S4A-D), and the overrepresented terms of MF, such as pigment binding (G0:0031409), chlorophyll binding (G0:0016168) (Fig. S5A-D), supported the identified DEGs were related to the photosynthetic modulation in response to drought stress. In addition, superoxide metabolism related GO terms superoxide metabolic process (G0:0006801) and regulation of superoxide metabolic process (G0:0090322) were highly enriched by which of the DEGs identified in point 20 of PR403, suggesting the involvement of the ROS scavenging processes in drought stress response (Fig. 4C). GO enrichment suggested that photosynthetic modulation played important role in the regulatory network of rice plants in response to drought stress, thereby chloroplast is the target organelle for drought stress response. 


\section{Construction of the co-expression network and identification of drought-induced hub genes}

To further investigate the impact of $d s s-1$ on the regulatory network in response to drought stress and to identify the specific genes that are highly correlated with drought-induced physiological alterations in rice, we performed WGCNA analysis. After removed the genes with low FPKM (FPKM<1), a total of 23178 genes was used to construct a scale-free co-expression network based on the soft-thresholding power of $\beta=12$ (Fig. S6). In the results of WGCNA, the clusters with highly inter-connected genes were defined as modules; and the genes in the same modules have high correlation coefficients among each other. A total of 26 modules were identified via the Dynamic Tree Cut method (core parameter: MEDissThres $=0.25$ ) (Fig. 5A). In the correlation of physiological traits with over-represented modules, the intriguing preferences were observed in the results of the correlation. In general, the modules including Black, Blue, and Tan were exhibited negatively correlated with the majority of physiological traits, whereas Royalblue, Brown, Red, Grey60, Orange, and Green modules were exhibited positively correlated with the traits, indicating that the genes clustered in a module have similar expression alternation pattern in response to drought stress (Fig. 5B). Considering the significant difference of the contents of $\mathrm{H}_{2} \mathrm{O}_{2}$ and MDA were observed during drought stress, we focused on the correlations of $\mathrm{H}_{2} \mathrm{O}_{2}$ and MDA with gene modules and identified hub genes that were highly correlated with the two drought-related physiological indicators (Fig. 2A, D, G; Fig. 5B, C, D). With the cut-off threshold of GS > 0.4, in the total of 26 modules, Black (741 genes; $\left.R^{2}=-0.69, P=3.0 \times 10^{-5}\right)$, Blue $\left(4810\right.$ genes; $\left.R^{2}=-0.57, P=9.0 \times 10^{-4}\right)$, Grey60 $\left(148 ; R^{2}=0.67, P=4.0 \times 10^{-5}\right)$, and Green (1099 genes; $\left.\mathrm{R}^{2}=0.61, P=3.0 \times 10^{-4}\right)$, were considered as the modules that were highly correlated with $\mathrm{H}_{2} \mathrm{O}_{2}$, and Red (913 genes; $\mathrm{R}^{2}=0.63, P=2.0 \times 10^{-4}$ ), Brown (3132 genes; $\mathrm{R}^{2}=0.56, P=1.0 \times$ $10^{-3}$ ), and Royalblue (45 genes; $\mathrm{R}^{2}=0.68, P=4.0 \times 10^{-5}$ ) modules were considered highly correlated with MDA (Fig. 5B, D). The genes in which the modules were clustered showed highly correlated with their respective modules (Fig. S7A, B). Furthermore, hub genes were identified based on the following cuttingoff thresholds, GS > 0.60 and MM $>0.80$ for Black, Blue, Green, and Royal blue module, and GS $>0.5$ and $M M>0.8$ were used for Grey 60 , Red, and Brown module according to the strengthen of threshold. After removed the genes with $\left|\log _{2} \mathrm{FC}\right|<1$, all the obtained hub genes were significantly differentially altered their expressions in PY6 and PR403 under drought stress and were highlighted in the further functional analysis (Fig. S10A-F; Table S4-1 -7). Hereafter, we designated these hub genes as DEHGs.

\section{Functional enrichment analysis of hub genes correlated with $\mathrm{H}_{2} \mathrm{O}_{2}$ accumulation}

GO enrichment analysis was performed to functional clustering of the hub genes in the modules that were highly correlated with $\mathrm{H}_{2} \mathrm{O}_{2}$. A total of 115 and 204 DEHGs were identified in Black and Blue modules, respectively (Table S4-1, -2). In line with the above-mentioned results, these hub genes were highly enriched in the GO terms, including chloroplast (G0:0009507), chloroplast envelope (G0:0009941), thylakoid (GO:0009579), chloroplast stroma (G0:0009570), chlorophyll binding (G0:0016168), photosynthesis (GO: G0:0015979), photosystem I (GO:0009522), photosynthesis, light harvesting 
(G0:0009765), and photosynthesis, light reaction (G0:0019684), that are related to photosynthesis (Qvalue $\leq$ 0.05) (Fig. S8A-B; Table S6-1, -2). Interestingly, in agreement with previous reports (Ma et al. 2016), the expression of the majority of the DEHGs in modules Black and Blue was down-regulated without remarkable $\log _{2} \mathrm{FC}$ differences ( $\left|\log _{2} \mathrm{FC}_{\mathrm{PY} 6}-\mathrm{Log}_{2} \mathrm{FC}_{\mathrm{PR} 403}\right| \geq 1, P<0.05$ ) observed between PY6 and PR403 during drought treatment (Fig. 6A, B; Fig. S10A,B), implying that PY6 and PR403 have a common drought responsive regulation and their photosynthetic activities were inhibited in response to the drought stress.

Grey60 module was enriched with 41 DEHGs (Table S4-3). The expression of most of them was elevated under drought stress (Fig. S10C). Among of which, eight genes were showed differential expression alterations with the remarkably different magnitudes at least in one sampling point between two genotypes, exhibiting a strong dynamic induction in response to drought treatment (|Log $\mathrm{FC}_{\mathrm{PY6}^{-}}$ $\log _{2} \mathrm{FC}_{\mathrm{PR} 403} \mid \geq 1, P<0.05$ ) (Fig. 6C; Table 2; Table S6-3). The expression of Os01G0842500 and Os03G0273200, both encoding the proteins that are similar to laccase and were enriched in GO terms apoplast (G0:0048046)/lignin catabolic process (G0:0046274)/cytoplasmic membrane-bounded vesicle (GO:0016023)/oxidoreductase activity (GO:0016491), was consistently enhanced in two points of both PY6 and PR403, and showed higher magnitudes in PY6 (particularly at point 20) (Fig. 6C; Table 2). Five genes (Os01G0702700, Os06G0131700, Os05G0543600, Os03G0433200, and Os04G0508500) which are annotated as transcription factors and mainly enriched in the $\mathrm{GO}$ terms including DNA binding (GO:0003677), sequence-specific DNA binding transcription factor activity (G0:0003700), and response to freezing (G0:0050826), were significantly consistently induced to a certain extent at point 22 and were down-regulated at point 20 in PR403, whereas they were significantly induced only at point 20 in PY6 with the exception of Os03G0433200 (Fig. 6C; Table 2). Os01G0702700, Os05G0543600, and Os04G0508500 are belonged to MYB family TFs, and Os06G0131700 is NAC TF. Recent study suggested that Os06G0131700 (OsSWN1) were related to secondary cell wall formation (Chai et al. 2015), implying that the secondary cell wall formation may play a certain role in drought stress resistance. In addition, Os08g0189200 is annotated as a gene encoding Germin-like protein 8-3 and was suggested involved in disease resistance (Davidson et al. 2010). A different up-regulated pattern of this gene was observed in PY6 and PR403 in response to drought stress (Fig. 6C; Table 2).

A total of 96 hub genes were identified in Green module, including 36 down-regulated and 60 up-regulated genes in response to drought (Fig. S10D; Table S4-4). G0 enrichment analysis showed that the majority of the over-represented $\mathrm{GO}$ terms are related to oxidation-reduction process (G0:0055114), response to salt stress (G0:0009651), carbohydrate metabolic process (G0:0005975), biosynthetic process (GO:0009058), and metabolic process (GO:0008152), etc. These hub genes were sub-localized to distinct cellular components and have various molecular functions (Fig. S8D; Table S6-4). However, no G0 term was significantly over-represented with the exception of iron-sulfur cluster binding (GO:0051536) in our analysis (Table S6-4). It's worth noting that only 1 hub gene OS04G0685300, encoding a protein with harpin-induced 1 domain, was showed significant differential expression alteration with a higher upregulated magnitude at two points of PY6 (2.03/2.67) by comparing with those in PR403 (Table S4-4). 
All these together, the functional annotation of the hub genes identified in the $\mathrm{H}_{2} \mathrm{O}_{2}$-related modules suggested both PY6 and PR403 experienced drought-triggered photosynthetic activity inhibition and led to the accumulation of $\mathrm{H}_{2} \mathrm{O}_{2}$ in rice plants. While the hub genes with highly differential expression alternations identified in Grey60 might be responsible for the accumulation of $\mathrm{H}_{2} \mathrm{O}_{2}$ in rice plants.

\section{Functional enrichment analysis of hub genes correlated with MDA accumulation}

MDA is an important indicator of membrane lipid peroxidation. Red, Brown, and Royal blue modules were highly correlated with MDA under drought treatment. There were 303, 304, and 13 hub genes were identified in these modules, respectively (Table S4-5 -7). For Red module, GO analysis showed that the hub genes involve in biotic stress and defense response (Fig. S9A; Table S6-5). Among these hub genes, 29 were showed differential expression alterations at least in one sampling point between two genotypes (|Log2FC $\left.\mathrm{FY}_{\mathrm{PY}}-\mathrm{Log}_{2} \mathrm{FC}_{\mathrm{PR} 403} \mid \geq 1, P<0.05\right)$ (Fig. 7A; Table 3). Strikingly, most of them consistently showed a similar expression pattern in both genotypes with the elevated transcripts at point 22 and then declined to comparable or even lower level in contrast to their respective untreated control (Fig. S10E; Table 3). GO analysis revealed that these genes involved in biotic stress responses, for example, the GO terms defense response, response to biotic stimulus, response to stress, and response to endogenous stimulus were over-represented in the results (Fig. 7A). Of which, 8 genes were belonged to WRKY family TFs (Fig. 7A; Table 3). Specifically, OsWRKY70 (Os05g0474800) and OsWRKY76 (Os09g0417600) were suggested to participate in ABA signaling and biotic stress response (Yokotani et al. 2013; Zhang et al. 2015). OS01g0185900 and OS05g0322900 were exhibited relative higher up-regulated expression at point 22, whereas another two genes OS05g0571200 and OS11G0117600 have relative higher expression at point 20 of PY6 by comparison with those in PR403 (Fig. 7A; Table 3); Considering the accumulation of MDA in PY6 and PR403, these implied that four genes might positively correlate with the over-accumulation of MDA and lead to the death of PY6 under drought stress. Moreover, PR-10a (OS12g0555300), which functions in the downstream of jasmonic acid pathway and is positively regulated by WRKY TFs in response to drought and high salt stresses (Takeuchi et al. 2016; Takeuchi et al. 2011), and three other PR-10 protein family hub genes (Os12g0555200, Os12g0555500, and Os12g0555000), which annotated as the genes encoding for PR10 family proteins probenazole-inducible protein PBZ1 that were involved in disease resistance, exhibited higher magnitude of the up-regulated expressions at two sampling points of PY6 in contrast to PR403 (Fig. 7A; Table 3). BSR-d1/ZFP36 (Os03g0437200), encoding $\mathrm{C}_{2} \mathrm{H}_{2}$-type zinc finger protein, participates in ABA-OsMPK transduction and results in the accumulation of $\mathrm{H}_{2} \mathrm{O}_{2}$ ( $\mathrm{Li}$ et al. 2017; Zhang et al. 2014). Similarly, it also has a higher up-regulated expression in PY6 than those in PR403 (Table 3). In addition, the expression of OS02g0121700 and OS02g0570400 was dramatically induced in PY 6 in the whole period of drought treatment, whereas they were only significantly induced in point 22 of PR403 and in turn lowered their level to untreated control (Fig. 7A; Table 3). They encode terpenoid synthase domain containing protein and ent-kaurene synthase $1 \mathrm{~A}$ that involve in gibberellins (GA) biosynthesis, respectively, suggesting the roles of GA played in drought stress response in rice. 
OS04g0109100, a gene was annotated as concanavalin A-like lectin/glucanase, has a similar expression pattern in both genotypes.

Totals of 18 and 13 DEHGs were identified in Brown and Royalblue modules, respectively (Fig. 7B, C; Table 4; Table S5). GO analysis revealed that the DEHGs in Brown module play different roles in diverse biological processes, including response to stress, response to endogenous stimulus, protein phosphorylation, protein metabolic process, lipid metabolic process, carbohydrate metabolic process, protein folding, regulation of transcription, and signal transduction (Fig. 7B; Table S6-6). Almost all of which were induced at point 22 and repressed at point 20 by drought in both genotypes. Although they have a similar alteration pattern, the different extent of the down-regulation was observed in several hub genes, for example OS11G0569300, OS01G0971800, OS04G0675400, and OS09G0243200 showed more lower extent of down-regulation at point 20 of PY6, while OS07G0201500 and OS11G0209600 showed more lower extent of down-regulation at point 20 of PR403 (Fig. 7B; Table S5). In module Royalblue, only one GO term was significantly over-represented due to the lesser number of DEHGs. The striking feature of the expression pattern of the hub genes was that their transcripts were dramatically induced by drought at point 22 of PY6 and they were also slightly reduced their levels in next sampling point. Interestingly, Os04g0494100 and Os11g0592200 were annotated as the genes encoding PR3 and PR4 family proteins that have plant chitinase activity. Os03g0663600 and 0s12g0630200 are two genes for encoding pathogenesis-related thaumatin-like proteins which is belonged to PR5 family, suggesting that the roles of these genes played in the cross talk between drought and biotic stresses in this study (Fig. 7C; Table 4; Table S6-7).

\section{Discussion}

In this study, a CSSL PY6 was adopted to characterize a QTL locus dss-1 for drought sensitive phenotype and to investigate the impact of $d s s-1$ on the reprogramming of transcriptional profiles of PY 6 in response to drought stress by RNA-seq and WGCNA analysis.

\section{Drought-induced the over-accumulation of $\mathrm{H}_{2} \mathrm{O}_{2}$ might lead to the sensitive phenotype of $d s s-1$}

Reactive oxygen species (ROS) (e.g. ${ }^{2 \cdot-}, \mathrm{H}_{2} \mathrm{O}_{2}, \mathrm{OH}^{\cdot},{ }^{1} \mathrm{O}_{2}$ ) is unavoidable toxic byproducts of plants in response to abiotic/biotic stresses (Choudhury et al. 2017). The over-accumulation of ROS in cells causes severe oxidative damage to membranes (lipid peroxidation), proteins, RNA, and DNA molecules (Mittler 2002). Higher plants have thus evolved dedicated scavenging pathways to protect themselves from ROS toxicity, including detoxifying enzymes, CAT, SOD, POD, and APX, as well as antioxidant ascorbate-glutathione (GSH) cycle (Mittler 2006; Mori and Schroeder 2004). In this study, the significant over-accumulation of $\mathrm{H}_{2} \mathrm{O}_{2}$ was detected in PY6 in contrasting to PR403 during drought treatment (Fig. $2 A, D)$. Regarding to the drought sensitive phenotype of PY6, which conferred by the introgression of $d s s-$ 1 into the background of PR403, our results suggested that the important relationships were evident 
among $d s s-1, \mathrm{H}_{2} \mathrm{O}_{2}$ accumulation, and sensitive phenotype. That is, we speculated that the introgression of $d s s-1$ might directly or indirectly lead to the over-accumulation of $\mathrm{H}_{2} \mathrm{O}_{2}$ in the rice cells. The overaccumulation of $\mathrm{H}_{2} \mathrm{O}_{2}$ causes oxidative damages to cell membrane (lipid peroxidation), which was reflected by the measurements of MDA, and others, and further leads to the death of rice plants under severe drought stress condition.

\section{Photosynthesis regulation, a common regulatory process for rice in response to drought stress}

Chloroplast is important organelle for the fixation of light energy for the life of higher plants, and any other life in our biosphere (Cai et al. 2019). Thus, photosynthesis is the major biological process occurred in chloroplast. Beyond its normal role in photosynthesis, the increasing evidence suggested that chloroplast is a targeted organelle that involves in environmental stress responses via positively or passively tuning the photosynthetic activity to adapt to the environmental changes (Gan et al. 2019). In GO enrichment analysis, the drought-induced DEGs identified either in PR403 or PY6 were mainly enriched in photosynthesis-related GO terms (Fig. 4; Fig. S4, S5); As well, the analysis of differentially expressed hub genes clustered in the modules Black and Blue showed that the similar set of GO terms that are related to photosynthesis process in chloroplasts were over-represented (Fig. S8A, B). In terms of the expression alteration during drought treatment, in line with previous studies (Ma et al. 2016), the majority of hub genes clustered in modules Black and Blue were consistently declined to a similar extent in both PY6 and PR403 (Fig. S10A, B), implying that the photosynthetic activity of both genotypes was dramatically inhibited in response to drought stress. The inhibition of photosynthesis reduces the utilization of absorbed light energy. The excess light energy results in the generation of toxic ROS (Kojima et al. 2007). Therefore, photosynthetic activity regulation could be a common regulatory process that are shared in diverse varieties for the adaptation of rice in response to environmental stresses. The inhibition of photosynthesis in both genotypes of this study might be correlated to the accumulation of $\mathrm{H}_{2} \mathrm{O}_{2}$ in rice cells. Regarding to the differential accumulation of $\mathrm{H}_{2} \mathrm{O}_{2}$ in the leaves of PY6 and PR403, it might result from the effect of the introgression of $d s s-1$ into the PR403 on the differential expression changes of the hub genes identified in other modules. Furthermore, previous studies considered that the improvement of the photosynthetic capacity was important for drought resistance in plants (Zhang et al. 2016). However, in this study, no significant expression difference was observed in the photosynthesis-related DEGs identified in both PR403 and PY6, suggesting that $d s s$-7-underlied the drought sensitive phenotype was not caused by the severe inhibition of photosynthesis, but by the over-accumulation of $\mathrm{H}_{2} \mathrm{O}_{2}$.

\section{$\mathrm{H}_{2} \mathrm{O}_{2}$-correlated hub genes differentially regulated in response to drought stress}

Transcription factors are key players in the regulatory networks for plant responding to unfavorable stresses. The MYB family is one of the largest transcription factor families in plants with a conserved 
MYB binding domain and it has been showed to be essential for plants in response to abiotic stresses ( $\mathrm{Li}$ et al. 2015), as well as, to be induced by $\mathrm{H}_{2} \mathrm{O}_{2}$ in soybean (Wang et al. 2017). In this study, five differentially expressed genes that are annotated as transcription factors, including 3 MYB, 1 NAD, and 1 SHR families, were highly clustered in Grey60, a module that was statistically correlated with the accumulation of $\mathrm{H}_{2} \mathrm{O}_{2}$ during drought stress. Among them, Os01G0702700, Os05G0543600, and Os04G0508500 are MYB family transcription factors. They were exhibited an elevated expression in both genotypes in response to drought stress (Table 2). However, three genes were showed a higher magnitude of up-regulations in the point 22 of PR403. Considering the lower accumulation of $\mathrm{H}_{2} \mathrm{O}_{2}$ and MDA in PR403, therefore, the MYB family TFs might be induced by drought stress or other signaling messengers and triggered the activation of downstream components of drought responsive signaling pathways, including the up-regulation of stress responsive genes which involve in increasing the content of osmoprotectants and the activities of the POD, CAT, and SOD, and maintain a sub-lethal content of $\mathrm{H}_{2} \mathrm{O}_{2}$ in plant cells during drought stress, suggesting that the MYB TFs identified here were positively correlated with drought resistance (Fig. 2; Fig. 6C; Table 2). In addition, strikingly, Os01G0842500 and Os03G0273200, both of which were annotated as putative laccase-encoded genes, were consistently exhibited elevated expression in both genotypes in response to drought. However, PY6 had a relative higher upregulated expression in the point 20, this implying the over-accumulation of the transcripts of the genes for laccase might be correlated to the drought sensitive phenotype of PY6. Paradoxically, the overexpression of another laccase-encoded gene OsChi1 (Os01g0827300) in Arabidopsis resulted in an increased tolerance to drought and salinity stresses (Cho et al. 2014). Thus, further study needs to be performed to explorer the function of the laccases identified in the study and reveals the discrepancy appeared here.

Moreover, it has been demonstrated that laccases were regulated by MYB TFs and involved in lignin biosynthesis in secondary wall formation of Arabidopsis and Miscanthus (He et al. 2019; Zhou et al. 2009); as well, a rice laccase encoding gene OsChi1 was reported that played an important role in the ROS signaling pathway (Cho et al. 2014), suggesting that, in present study, MYB TFs-regulated laccases with the differential expression alteration participated in the improvement of drought stress tolerance (Fig. 8).

\section{MDA-correlated hub genes differentially regulated in response to drought stress}

The majority of DEHGs clustered in the modules that were highly correlated with MDA have been showed to be involved in plant defence signaling pathways. These included WRKY family TFs and PR family proteins (Table 3-4; Table S5). In general, 8 differentially expressed WRKY TFs identified in Red module, in contrast to PR403, were showed a higher degree of induction at point 22 and a lowered level at point 20 in PY6 (Table 3). Similarly, four members of PR10 family encoding genes identified in Red module, and three other families of PR proteins (PR3, PR4, and PR5) identified in Royalblue module exhibited similar alteration pattern in response to drought stress. These suggested that a cross talk existed between 
abiotic and biotic stress responsive pathways during drought stress. Recent reports revealed that some common components were shared by the signaling pathways for abiotic and biotic stress responses, including the phytohormones abscisic acid, salicylic acid, and josmonic acid, the cis-acting regulatory elements, and protein kinase cascades (Verma et al. 2016). Plants can rapidly respond to environmental changes by the synergistical or antagonistic regulations of the cross talks among the pathways via their convergent nodes (Verma et al. 2016). OsWRKY76 (OS09G0417600), one of a hub gene of Red module, encodes a group lla WRKY TFs in rice. It has been showed that overexpression of OsWRKY76 in rice plants suppressed a specific set of PR genes and elevated the expression of abiotic stress-associated genes, and thereby, resulted in the increased susceptibility to $M$. oryzae, whereas improved tolerance to chilling stress (Yokotani et al. 2013). Moreover, OsWRKY13 was suggested to regulate the antagonistic cross talk between drought and disease resistance pathways via the repressions of SNAC1 and WRKY451 (Xiao et al. 2013). For the group of identified PR encoding genes, OS12G0555000 (RSOSPR10), a gene encoding rice root-specific pathogenesis-related protein PBZ1, was induced by drought and salinity stresses, as well as jasmonic acid; however, it was strongly inhibited by salicylic acid (Takeuchi et al. 2016; Takeuchi et al. 2011). Moreover, the expression of RSOSPR10 was postulated to repress by SAinduced OSTGAs or OSWRKYS (Takeuchi et al. 2011). Thus, WRKY TFs and PR family proteins encoded genes identified here might act as the convergent nodes and be responsible for the cross talks between abiotic and biotic stresses. In addition, ZFP36 (OS03G0437200), a gene encoding C2H2 Zinc finger protein (Brs-d1), is a key factor for regulating rice cell redox status and involves in ABA-induced upregulation of the expressions and the activities of SOD and APX. Overexpression of ZFP36 enhanced the tolerance to drought and oxidative stresses, but reduced the resistance to rice blast (Li et al. 2017; Zhang et al. 2014). However, a dramatic elevated expression of ZFP36 was exhibited in drought sensitive genotype PY6, suggesting it might play a synergistical role in the regulating network with WRKY TFs and PRs for rice plants in response to drought stress.

\section{The impact of $d s s-1$ on the reprogramming of hub genes in response to drought stress}

Taken all these together, hence, a working model was proposed here to depict the $d s s-1$ mediated possible mechanism for rice plants in response to drought stress at transcriptional level (Fig. 8). When rice exposed to severe drought stress, stress-induced the dehydration of rice plants and the stomatal closure of leaf guard cells result in the inhibition of photosynthesis activity and enhancing the ABA biosynthesis. The inhibition of photosynthesis reduces the utilization of absorbed light energy and results in the generation of toxic ROS, including $\mathrm{H}_{2} \mathrm{O}_{2}$. Overaccumulation of ROS can oxidative stress damage to the plant cells and lead to the drought sensitive phenotype of rice. Drought stress signal, the accumulated $A B A$, and $\mathrm{H}_{2} \mathrm{O}_{2}$ signal are integrated and perceived by rice cells and triggered the activation of responsive signaling pathways. First, the expression of series of TFs, including MYBs, WRKYs, ZFP36, NAC, etc., were differentially reprogrammed and induced the cross talk between drought and biotic stresses. Then, the induction of TFs regulates the expression of downstream responsive genes, including a number of PR family proteins, laccases, and among others, to mobilize multi facet of the resources in vivo to respond to 
drought stress, and eventually lowers the content of ROS in plant cells and ameliorates the droughtinduced sensitive phenotype of rice. The introgressed $d s s-1$ might exert its effect on the hub genes which were identified in our study to differentially reprogram of their expressions, and therefore leading to the differential accumulation of ROS in drought resistance and sensitive varieties. The differential activation of ROS-related responsive pathways that would diverge the drought resistance/sensitive phenotypes of rice varieties.

\section{Conclusion}

Taken together, our results suggested that chloroplast is the targeted organelle for PR403 and PY6 in response to drought stress regulation. Functional annotation analysis of the hub genes in the modules that were highly correlated with $\mathrm{H}_{2} \mathrm{O}_{2}$ and MDA accumulations during drought treatment provided us a global picture for the impact of $d s s-1$ on the reprogramming of regulatory mechanism (s) at transcriptional level. Specifically, the differential expression patterns of $M Y B s, W R K Y S$, PR protein, and ZFP36, etc., showed in both genotypes suggested their roles in the variation of ROS and MDA accumulations, and thereby resulting the sensitive phenotype of rice in response to drought stress.

\section{Materials And Methods}

\section{Plant materials, growth, and treatment conditions}

The growth of rice seedlings were performed according to previously described methods (Cen et al. 2018) with minor modification. In brief, rice plants were grown in the equal amount of paddy soil. As well, equal amount of water was watered routinely. The drought treatment was performed according to the methods as described (Zong et al. 2016). Soil moisture was monitored regularly to determine the stages of drought stress using EM-WSYP soil moisture detector (Hengmei Company, Shandong, China). The leaves of 3-

week old soil-cultured rice seedlings (three biological replicates) in the greenhouse (day $35{ }^{\circ} \mathrm{C} / \mathrm{night} 30^{\circ} \mathrm{C}$ ) were collected at four soil moisture points, 40 (soil moisture percentage $40 \%$, represent well-watered condition), 22 (soil moisture percentage $22 \%$, drought treatment $96 \mathrm{~h}$ from $40 \%$ soil moisture), 20 (soil moisture percentage $20 \%$, drought treatment $120 \mathrm{~h}$ ), and 15 (soil moisture percentage $15 \%$, drought treatment 168h) (Fig. S1) and snap frozen in liquid-nitrogen for RNA-seq and physiological index measurement, respectively. The samples harvested at point 15 were only for physiological measurement analysis. Drought stress treatment for hydroponically cultured seedlings in 96-well plates was performed in rice nutrient solution supplemented with $20 \%$ (w/v) PEG 6000. Survival rate was determined after 5-day treatment and re-watered for 3 days, respectively.

\section{RNA-seq library construction and transcriptomic data processing}

The library of transcriptome was generated by NEBNext ${ }^{\circledR}$ UltraTM RNA Library Prep Kit for Illumina ${ }^{\circledR}$ (NEB, USA) following manufacturer's instruction. After digestion, purification, and PCR amplification, 
cDNA fragment (250 300bp) was purified by AMPure XP beads. The cDNA sequencing was performed on an Illumina 2500 platform, and paired-end reads were generated. After removed low quality reads from data, the clean reads were mapping to the reference genome (the rice annotation project database, https://rapdb.dna.affrc.go.jp/index.html). DEGs between each treated point and untreated control were detected using DEseq with $\mid \log 2 \mathrm{FCl} \geq 1$ (FC, the abbreviation of fold change) and padj $\leq 0.05$ as thresholds to identify drought- induced DEGs, respectively. As well, the development-dependent DEGs were detected in the same sampling points of well-watered samples with the same criterion. As the development-dependent DEGs could be caused by the development of rice plants, they were excluded from the final dataset.

The Go enrichment analysis were performed on PlantRegMap (http://plantregmap.cbi.pku.edu.cn/). The over-represented GOs were visualized using ggplot2 and GOplot R package (Walter et al. 2015). Heatmap was generated by MEV v4.9 (Saeed et al. 2003).

\section{Co-expression network analysis}

The WGCNA R-package was used to construct co-expression network and analyze the correlation of modules and physiological data according to the method as described (Langfelder and Horvath 2008). Raw transcriptomic datasets of all samples were filtered to remove any genes with an FPKM $<1$ even in one replicate of either sampling point of the samples. Clean data was used to generate co-expression network. First, the soft threshold power was estimated by the pickSoftThreshold function, which provides the appropriate soft-thresholding power for network construction. Second, a correlation matrix was constructed based on obtained soft threshold power, and in turn calculated topological overlap matrix (TOM) from the transformed correlation matrix. Finally, the genes were grouped based on the topological overlap dissimilarity (1-TOM) by average hierarchical clustering using hclust function. Gene modules were then identified using a dynamic tree cut algorithm (minimum cluster size 30, merging threshold function 0.25). Module membership (MM) was calculated based on Pearson correlation between the expression level and the module eigengenes to identify hub genes within the modules. Genes with higher MM indicate the genes with higher connectivity within the module.

To correlate the physiological data with the network, module eigengenes were correlated with each physiological data, respectively. Gene significance (GS) was used to correlate physiological data with the expression data of individual genes.

\section{Genome-wide association study analysis}

A total of 84 varieties are selected from 3024 diverse accessions of 3K project (Wang et al. 2018). The SNPs information was obtained from public database (IRRI, http://irri.org/). GWAS analysis for survival rate were using Efficient Mixed-Model Association eXpedited (EMMAX) software package. 


\section{Analysis of the movement of the stomatal aperture}

Four-week seedlings were selected for scanning electron microscopy (SEM) analysis. The middle part of penultimate leaves was cut into $0.5-\mathrm{cm}$ pieces in length and snap frozen with liquid nitrogen to maintain the stomatal morphology. FEI QRATRO S scanning electron microscope (Thermo Fisher Scientific, USA) with a freezing stage was used to examine the leaf stomatal apertures. The opening status and density of stomata were analyzed with Image $\mathrm{J}$ software. Four random fields were selected to count the number of stomata in each replicate.

\section{Quantitative real time reverse transcription PCR analysis}

Total RNA was isolated from leaves samples (three biological replicates per sample). cDNA synthesis was performed by reverse transcription (RT) with the Thermo Scientific Revert Aid First Strand cDNA Synthesis Kit (Cat\# K1622) according to the manufacturer's protocol. The sequences of genes were downloaded from RAP-DB (https://rapdb.dna.affrc.go.jp/index.html). The primers for related genes were obtained from qPrimerDB (https://biodb.swu.edu.cn/qprimerdb/) (Table S1) (Lu et al. 2018). qPCR was performed on a Roche Lightcycler 480 Real-Time PCR System in $10 \mu \mathrm{L}$ reactions with the SYBR Green PCR Master Mix kit (BIORAD, USA), following the manufacture's protocol. The relative expression of each gene was calculated according to the $2^{-\triangle \triangle C T}$ method (Livak and Schmittgen 2001). The actin gene (Os11g0163100) was used as internal reference for analysis.

\section{Determination of relative water content of leaves}

The leaf samples were collected at each sampling point and weighted to determine the fresh weight (FW). Then oven-dried to a constant dry weight (DW). The relative water content was calculated according to RWC $(\%)=[(F W-D W) / F W] \times 100 \%$.

\section{Examination of $A B A$, ROS and its scavenging enzyme activity}

A total of $0.15 \mathrm{~g}$ fresh leaf samples of PR403 and PY6 were collected and ground in liquid nitrogen into fine powder, and then resuspended in $1.35 \mathrm{ml}$ PBS buffer $(10 \mathrm{mM}, \mathrm{pH} 7.2)$. After centrifugation at 5000 rpm for 5 min, the supernatant was collected for subsequent assay. The contents and activity of $\mathrm{H}_{2} \mathrm{O}_{2}$, SOA, ABA, SOD, CAT, POD, and APX were measured using an enzyme-linked immunosorbent assay (ELISA) kit (Mskbio Company, Wuhan, China) following the manufacturer's instruction. 
3,3'-Diaminobenzidine (DAB) staining was performed to detect the accumulation of $\mathrm{H}_{2} \mathrm{O}_{2}$ in leaves. The leaves of 3-week old seedlings were collected for staining. Samples were vacuum-infiltrated for $10 \mathrm{~min}$, then incubated in DAB solution ( $1 \mathrm{mg} / \mathrm{mL}$ in water, $\mathrm{pH} 5.8)$ for $12 \mathrm{~h}$ in the dark. For the detection of superoxide, leaf pieces were vacuum-infiltrated as described above in $0.1 \%$ nitroblue tetrazolium (NBT) with $0.1 \%$ Triton $\mathrm{X}-100$ in $10 \mathrm{mM}$ of phosphate buffer $(\mathrm{pH} 7.2)$ for $10 \mathrm{~min}$. Then the samples were boiled in absolute ethanol to remove the chlorophyll (Cen et al. 2018).

\section{Declarations}

Compliance and ethics The author(s) declare that they have no conflict of interest.

\section{Acknowledgments}

Much appreciate Prof. Lijun Luo, a senior researcher of Shanghai Academy of Agricultural Sciences, for providing parental rice seeds. We thank the reviewers and editors for the careful reading of our manuscript and constructive comments, and appreciate the technical assistance of the scientific instrument platform of the State Key Laboratory for Conservation and Utilization of Subtropical Agrobioresources (Guangxi University) for performing SEM analysis in this study.

\section{Author contributions}

$\mathrm{JL}$ and RL conceived and designed the experiments. BY, JBL, DW, YL, and WC performed all the lab experiments. BY, JBL, and DW conducted the field trials and collected samples for RNA-Seq. JL, BY, and WC performed the data processing. JL drafted the manuscript. JL, RL, BY, and SW revised the manuscript. All authors approved the final version of the manuscript.

\section{Funding}

The research was supported by grants from the National Natural Science Foundation of China (CN) (31671646); Guangxi Hundred-Talents Program (2015); Guangxi innovation-driven development special funding project (Guike-AA17204070); and the State Key Laboratory for Conservation and Utilization of Subtropical Agro-Bioresources (SKLCUSA-a201907, -a201918, and -a201801).

\section{Availability of data and material}


All data supporting the conclusion of this paper can be obtained from the corresponding authors under reasonable requirements.

\section{Ethics approval and consent to participate}

Not applicable.

\section{Consent for publication}

Not applicable.

\section{Competing interests}

The authors declare that they have no competing interests.

\section{Author details}

1. College of Life Science and technology (State Key Laboratory for Conservation and Utilization of Subtropical Agro-bioresources), Guangxi University, Nanning 530004, China

2. Agriculture College, Guangxi University, Nanning 530004, China

3. Agriculture College, South China Agricultural University, Guangzhou 510642, China

\section{References}

Agarwal P, Agarwal PK (2014) Pathogenesis related-10 proteins are small, structurally similar but with diverse role in stress signaling. Mol Biol Rep 41: 599-611

Bailey-Serres J, Parker JE, Ainsworth EA, Oldroyd GED, Schroeder JI (2019) Genetic strategies for improving crop yields. Nature 575: 109-118

Borah P, Sharma E, Kaur A, Chandel G, Mohapatra T, Kapoor S, Khurana JP (2017) Analysis of droughtresponsive signalling network in two contrasting rice cultivars using transcriptome-based approach. Sci Rep 7: 42131

Cai Z, Jia P, Zhang J, Gan P, Shao Q, Jin G, Wang L, Jin J, Yang J, Luo J (2019) Genetic analysis and fine mapping of a qualitative trait locus wpb1 for albino panicle branches in rice. PLoS One 14: e0223228 
Cen W, Liu J, Lu S, Jia P, Yu K, Han Y, Li R, Luo J (2018) Comparative proteomic analysis of QTL CTS-12 derived from wild rice (Oryza rufipogon Griff.), in the regulation of cold acclimation and de-acclimation of rice (Oryza sativa L.) in response to severe chilling stress. BMC Plant Biol 18: 163

Chai M, Bellizzi M, Wan C, Cui Z, Li Y, Wang G-L (2015) The NAC transcription factor OsSWN1 regulates secondary cell wall development in Oryza sativa. J Plant Biol 58: 44-51

Cho HY, Lee C, Hwang SG, Park YC, Lim HL, Jang CS (2014) Overexpression of the OsChl1 gene, encoding a putative laccase precursor, increases tolerance to drought and salinity stress in transgenic Arabidopsis. Gene 552: 98-105

Choudhury FK, Rivero RM, Blumwald E, Mittler R (2017) Reactive oxygen species, abiotic stress and stress combination. Plant J 90: 856-867

Clarke C, Madden SF, Doolan P, Aherne ST, Joyce H, O'driscoll L, Gallagher WM, Hennessy BT, Moriarty M, Crown J, Kennedy S, Clynes M (2013) Correlating transcriptional networks to breast cancer survival: a large-scale coexpression analysis. Carcinogenesis 34: 2300-2308

Davidson RM, Manosalva PM, Snelling J, Bruce M, Leung H, Leach JE (2010) Rice Germin-Like Proteins: Allelic Diversity and Relationships to Early Stress Responses. Rice 3: 43-55

De Zelicourt A, Colcombet J, Hirt H (2016) The Role of MAPK Modules and ABA during Abiotic Stress Signaling. Trends Plant Sci 21: 677-685

Deng T, Liang A, Liang S, Ma X, Lu X, Duan A, Pang C, Hua G, Liu S, Campanile G, Salzano A, Gasparrini B, Neglia G, Liang X, Yang L (2019) Integrative Analysis of Transcriptome and GWAS Data to Identify the Hub Genes Associated With Milk Yield Trait in Buffalo. Front Genet 10: 36

Du J, Wang S, He C, Zhou B, Ruan YL, Shou H (2017) Identification of regulatory networks and hub genes controlling soybean seed set and size using RNA sequencing analysis. J Exp Bot 68: 1955-1972

Foyer $\mathrm{CH}$, Noctor $\mathrm{G}$ (2000) Oxygen processing in photosynthesis: regulation and signalling. New Phytol 146: $359-388$

Gan P, Liu F, Li R, Wang S, Luo J (2019) Chloroplasts- Beyond Energy Capture and Carbon Fixation: Tuning of Photosynthesis in Response to Chilling Stress. Int J Mol Sci 20: 5046

Greenham K, Mockler TC, Weinig C, Guadagno CR, Ewers BE, Gehan MA, Mcclung CR (2017) Temporal network analysis identifies early physiological and transcriptomic indicators of mild drought in Brassica rapa. eLIFE 6: e29655

Group RWW (2012) Nomenclature report on rice WRKY's - Conflict regarding gene names and its solution. Rice 5: 3 
He F, Machemer-Noonan K, Golfier P, Unda F, Dechert J, Zhang W, Hoffmann N, Samuels L, Mansfield SD, Rausch T, Wolf S (2019) The in vivo impact of MsLAC1, a Miscanthus laccase isoform, on lignification and lignin composition contrasts with its in vitro substrate preference. BMC Plant Biol 19: 552

Hu H, Xiong L (2014) Genetic engineering and breeding of drought-resistant crops. Annu Rev Plant Biol 65: 715-741

Huang L, Chen L, Wang L, Yang Y, Rao Y, Ren D, Dai L, Gao Y, Zou W, Lu X, Zhang G, Zhu L, Hu J, Chen G, Shen L, Dong G, Gao Z, Guo L, Qian Q, Zeng D (2019) A Nck-associated protein 1-like protein affects drought sensitivity by its involvement in leaf epidermal development and stomatal closure in rice. Plant $\mathrm{J}$ 98: 884-897

Huang XY, Chao DY, Gao JP, Zhu MZ, Shi M, Lin HX (2009) A previously unknown zinc finger protein, DST, regulates drought and salt tolerance in rice via stomatal aperture control. Genes Dev 23: 1805-1817

Huber AE, Melcher PJ, Pineros MA, Setter TL, Bauerle TL (2019) Signal coordination before, during and after stomatal closure in response to drought stress. New Phytol. 224: 675-688

Kim TW, Youn JH, Park TK, Kim EJ, Park CH, Wang Z, Kim SK, Kim TW (2018) OST1 Activation by the Brassinosteroid-Regulated Kinase CDG1-Like 1 in Stomatal Closure. Plant Cell 30: 1848-1863

Kojima K, Oshita M, Nanjo Y, Kasai K, Tozawa Y, Hayashi H, Nishiyama Y (2007) Oxidation of elongation factor $\mathrm{G}$ inhibits the synthesis of the D1 protein of photosystem II. Mol Microbiol 65: 936-947

Langfelder P, Horvath S (2008) WGCNA: an R package for weighted correlation network analysis. BMC Bioinformatics 9: 559

Li C, Ng CKY, Fan L-M (2015) MYB transcription factors, active players in abiotic stress signaling. Environ Exp Bot 114: 80-91

Li W, Zhu Z, Chern M, Yin J, Yang C, Ran L, Cheng M, He M, Wang K, Wang J, Zhou X, Zhu X, Chen Z, Wang J, Zhao W, Ma B, Qin P, Chen W, Wang Y, Liu J, Wang W, Wu X, Li P, Wang J, Zhu L, Li S, Chen X (2017) A Natural Allele of a Transcription Factor in Rice Confers Broad-Spectrum Blast Resistance. Cell 170: 114126 e115

Lilley JM, Ludlow MM, Mccouch SR, O'toole JC (1996) Locating QTL for osmotic adjustment and dehydration tolerance in rice. J Exp Bot 47: 1427-1436

Liu C, Mao B, Ou S, Wang W, Liu L, Wu Y, Chu C, Wang X (2014) OsbZIP71, a bZIP transcription factor, confers salinity and drought tolerance in rice. Plant Mol Biol 84: 19-36

Liu J-J, Ekramoddoullah AKM (2006) The family 10 of plant pathogenesis-related proteins: Their structure, regulation, and function in response to biotic and abiotic stresses. Physiol Mol Plant P 68: 3-13 
Liu J, Zhang C, Wei C, Liu X, Wang M, Yu F, Xie Q, Tu J (2016) The RING Finger Ubiquitin E3 Ligase OsHTAS Enhances Heat Tolerance by Promoting H2O2-Induced Stomatal Closure in Rice. Plant Physiol 170: 429-443

Livak KJ, Schmittgen TD (2001) Analysis of relative gene expression data using real-time quantitative PCR and the 2(- $\triangle \mathrm{C}(\mathrm{T}))$ Method. Methods 25: 402-408

Lou Q, Chen L, Mei H, Wei H, Feng F, Wang P, Xia H, Li T, Luo L (2015) Quantitative trait locus mapping of deep rooting by linkage and association analysis in rice. J Exp Bot 66: 4749-4757

Lu K, Li T, He J, Chang W, Zhang R, Liu M, Yu M, Fan Y, Ma J, Sun W, Qu C, Liu L, Li N, Liang Y, Wang R, Qian W, Tang Z, Xu X, Lei B, Zhang K, Li J (2018) qPrimerDB: a thermodynamics-based gene-specific qPCR primer database for 147 organisms. Nucleic Acids Res 46: D1229-D1236

Luo LJ (2010) Breeding for water-saving and drought-resistance rice (WDR) in China. J Exp Bot 61: 35093517

Ly H, F Z, F Z, Ws W, YI Z, By F, Zk L (2014) Comparative transcriptome sequencing of tolerant rice introgression line and its parents in response to drought stress. BMC Genomics 1026: 1026

Ma X, Xia H, Liu Y, Wei H, Zheng X, Song C, Chen L, Liu H, Luo L (2016) Transcriptomic and Metabolomic Studies Disclose Key Metabolism Pathways Contributing to Well-maintained Photosynthesis under the Drought and the Consequent Drought-Tolerance in Rice. Front Plant Sci 7: 1886

Mittler R (2002) Oxidative stress, antioxidants and stress tolerance. Trends in Plant Sci 7: 405-410 Mittler R (2006) Abiotic stress, the field environment and stress combination. Trends Plant Sci 11: 15-19

Mori IC, Schroeder JI (2004) Reactive oxygen species activation of plant Ca2+ channels. A signaling mechanism in polar growth, hormone transduction, stress signaling, and hypothetically mechanotransduction. Plant Physiol 135: 702-708

Okamoto M, Peterson FC, Defries A, Park SY, Endo A, Nambara E, Volkman BF, Cutler SR (2013) Activation of dimeric ABA receptors elicits guard cell closure, ABA-regulated gene expression, and drought tolerance. Proc Natl Acad Sci U S A 110: 12132-12137

Okay S, Derelli E, Unver T (2014) Transcriptome-wide identification of bread wheat WRKY transcription factors in response to drought stress. Mol Genet Genomics 289: 765-781

Ramachandra Reddy A, Chaitanya KV, Vivekanandan M (2004) Drought-induced responses of photosynthesis and antioxidant metabolism in higher plants. J Plant Physiol 161: 1189-1202

Robinson JM, Bunce JA (2000) Influence of Drought-Induced Water Stress on Soybean and Spinach Leaf Ascorbate-Dehydroascorbate Level and Redox Status. Int J Plant Sci 161: 271-279 
Ross CA, Liu Y, Shen QJ (2007) The WRKY Gene Family in Rice (Oryza sativa). J Integr Plant Biol 49: 827842

Saeed Al, Sharov V, White J, Li J, Liang W, Bhagabati N, Braisted J, Klapa M, Currier T, Thiagarajan M, Sturn A, Snuffin M, Rezantsev A, Popov D, Ryltsov A, Kostukovich E, Borisovsky I, Liu Z, Vinsavich A, Trush V, Quackenbush J (2003) TM4: A Free, Open-Source System for Microarray Data Management and Analysis. BioTechniques 34: 374-378

Sah SK, Reddy KR, Li J (2016) Abscisic Acid and Abiotic Stress Tolerance in Crop Plants. Front Plant Sci. 7: 571

Shaik R, Ramakrishna W (2013) Genes and co-expression modules common to drought and bacterial stress responses in Arabidopsis and rice. PLoS One 8: e77261

Shim JS, Oh N, Chung PJ, Kim YS, Choi YD, Kim JK (2018) Overexpression of OsNAC14 Improves Drought Tolerance in Rice. Front Plant Sci 9: 310

Takeuchi K, Hasegawa H, Gyohda A, Komatsu S, Okamoto T, Okada K, Terakawa T, Koshiba T (2016) Overexpression of RSOsPR10, a root-specific rice PR10 gene, confers tolerance against drought stress in rice and drought and salt stresses in bentgrass. Plant Cell Tiss Org 127: 35-46

Takeuchi K, Gyohda A, Tominaga M, Kawakatsu M, Hatakeyama A, Ishii N, Shimaya K, Nishimura T, Riemann M, Nick P, Hashimoto M, Komano T, Endo A, Okamoto T, Jikumaru Y, Kamiya Y, Terakawa T, Koshiba T (2011) RSOsPR10 expression in response to environmental stresses is regulated antagonistically by jasmonate/ethylene and salicylic acid signaling pathways in rice roots. Plant Cell Physiol 52: 1686-1696

Tang N, Ma S, Zong W, Yang N, Lv Y, Yan C, Guo Z, Li J, Li X, Xiang Y, Song H, Xiao J, Li X, Xiong L (2016) MODD Mediates Deactivation and Degradation of OsbZIP46 to Negatively Regulate ABA Signaling and Drought Resistance in Rice. Plant Cell 28: 2161-2177

Uga Y, Sugimoto K, Ogawa S, Rane J, Ishitani M, Hara N, Kitomi Y, Inukai Y, Ono K, Kanno N, Inoue H, Takehisa H, Motoyama R, Nagamura Y, Wu J, Matsumoto T, Takai T, Okuno K, Yano M (2013) Control of root system architecture by DEEPER ROOTING 1 increases rice yield under drought conditions. Nat Genet 45: 1097-1102

Varoquaux N, Cole B, Gao C, Pierroz G, Baker CR, Patel D, Madera M, Jeffers T, Hollingsworth J, Sievert J, Yoshinaga Y, Owiti JA, Singan VR, Degraaf S, Xu L, Blow MJ, Harrison MJ, Visel A, Jansson C, Niyogi KK, Hutmacher R, Coleman-Derr D, O'malley RC, Taylor JW, Dahlberg J, Vogel JP, Lemaux PG, Purdom E (2019) Transcriptomic analysis of field-droughted sorghum from seedling to maturity reveals biotic and metabolic responses. Proc Natl Acad Sci U S A 116: 27124-27132 
Verma V, Ravindran P, Kumar PP (2016) Plant hormone-mediated regulation of stress responses. BMC Plant Biol 16: 86

Walter W, Sanchez-Cabo F, Ricote M (2015) GOplot: an R package for visually combining expression data with functional analysis. Bioinformatics 31: 2912-2914

Wang N, Zhang W, Qin M, Li S, Qiao M, Liu Z, Xiang F (2017) Drought Tolerance Conferred in Soybean (Glycine max. L) by GmMYB84, a Novel R2R3-MYB Transcription Factor. Plant Cell Physiol 58: 1764-1776

Wang P, Zhao Y, Li Z, Hsu CC, Liu X, Fu L, Hou YJ, Du Y, Xie S, Zhang C, Gao J, Cao M, Huang X, Zhu Y, Tang K, Wang X, Tao WA, Xiong Y, Zhu JK (2018) Reciprocal Regulation of the TOR Kinase and ABA Receptor Balances Plant Growth and Stress Response. Mol Cell 69: 100-112 e106

Wang W, Mauleon R, Hu Z, Chebotarov D, Tai S, Wu Z, Li M, Zheng T, Fuentes RR, Zhang F, Mansueto L, Copetti D, Sanciangco M, Palis KC, Xu J, Sun C, Fu B, Zhang H, Gao Y, Zhao X, Shen F, Cui X, Yu H, Li Z, Chen M, Detras J, Zhou Y, Zhang X, Zhao Y, Kudrna D, Wang C, Li R, Jia B, Lu J, He X, Dong Z, Xu J, Li Y, Wang M, Shi J, Li J, Zhang D, Lee S, Hu W, Poliakov A, Dubchak I, Ulat VJ, Borja FN, Mendoza JR, Ali J, Li J, Gao Q, Niu Y, Yue Z, Naredo MEB, Talag J, Wang X, Li J, Fang X, Yin Y, Glaszmann JC, Zhang J, Li J, Hamilton RS, Wing RA, Ruan J, Zhang G, Wei C, Alexandrov N, Mcnally KL, Li Z, Leung H (2018) Genomic variation in 3,010 diverse accessions of Asian cultivated rice. Nature 557: $43-49$

Wang Z, Wang F, Hong Y, Huang J, Shi H, Zhu JK (2016) Two Chloroplast Proteins Suppress Drought Resistance by Affecting ROS Production in Guard Cells. Plant Physiol 172: 2491-2503

Xiao J, Cheng H, Li X, Xiao J, Xu C, Wang S (2013) Rice WRKY13 regulates cross talk between abiotic and biotic stress signaling pathways by selective binding to different cis-elements. Plant Physiol 163: 18681882

Xu PL, Guo YK, Bai JG, Shang L, Wang XJ (2008) Effects of long-term chilling on ultrastructure and antioxidant activity in leaves of two cucumber cultivars under low light. Physiol Plant 132: 467-478

Yokotani N, Sato Y, Tanabe S, Chujo T, Shimizu T, Okada K, Yamane H, Shimono M, Sugano S, Takatsuji H, Kaku H, Minami E, Nishizawa Y (2013) WRKY76 is a rice transcriptional repressor playing opposite roles in blast disease resistance and cold stress tolerance. J Exp Bot 64: 5085-5097

Zhang B, Horvath S (2005) A general framework for weighted gene co-expression network analysis. Stat Appl Genet Mol Biol 4: 17

Zhang H, Liu Y, Wen F, Yao D, Wang L, Guo J, Ni L, Zhang A, Tan M, Jiang M (2014) A novel rice C2H2-type zinc finger protein, ZFP36, is a key player involved in abscisic acid-induced antioxidant defence and oxidative stress tolerance in rice. J Exp Bot 65: 5795-5809

Zhang L, Gu L, Ringler P, Smith S, Rushton PJ, Shen QJ (2015) Three WRKY transcription factors additively repress abscisic acid and gibberellin signaling in aleurone cells. Plant Sci 236: 214-222 
Zhang X, Feng H, Li Z, Li D, Liu S, Huang H, Li M (2018) Application of weighted gene co-expression network analysis to identify key modules and hub genes in oral squamous cell carcinoma tumorigenesis. Onco Targets Ther 11: 6001-6021

Zhang Z-F, Li Y-Y, Xiao B-Z (2016) Comparative transcriptome analysis highlights the crucial roles of photosynthetic system in drought stress adaptation in upland rice. Scientific Reports 6: 19349

Zhou J, Lee C, Zhong R, Ye ZH (2009) MYB58 and MYB63 are transcriptional activators of the lignin biosynthetic pathway during secondary cell wall formation in Arabidopsis. Plant Cell 21: 248-266

Zhou XG, Huang XL, Liang SY, Tang SM, Wu SK, Huang TT, Mo ZN, Wang QY (2018) Identifying miRNA and gene modules of colon cancer associated with pathological stage by weighted gene co-expression network analysis. Onco Targets Ther 11: 2815-2830

Zhu X, Xiong L (2013) Putative megaenzyme DWA1 plays essential roles in drought resistance by regulating stress-induced wax deposition in rice. Proc Natl Acad Sci U S A 110: 17790-17795

Zong W, Tang N, Yang J, Peng L, Ma S, Xu Y, Li G, Xiong L (2016) Feedback Regulation of ABA Signaling and Biosynthesis by a bZIP Transcription Factor Targets Drought-Resistance-Related Genes. Plant Physiol 171: 2810-2825

\section{Supporting Information}

Fig. S1 Diagram showing the sampling points and the corresponding phenotypes of the plant materials.

Fig. S2 Determination of APX activity, endogenous ABA level, and stomatal status of PR403 and PY6 under drought treatment. a APX activity. b NBT staining of leaf samples. $\mathbf{c}$ Endogenous ABA content. $\mathbf{d}$ Leaf stomatal opening status during drought treatment. Top panel shows three levels: completely open, partially open and completely closed the aperture of stomata. Bottom panel shows the percentages of three levels of stomatal opening in PY6 and PR403 ( $n=100$ stomata for PR403 and PY6, respectively). Data in a and $\mathrm{b}$ are presented as mean $\pm S D(n=3, * P<0.05, * \star P<0.01$, Student's $t$ test. Scale bars $=0.5$ $\mathrm{cm}$ in $\mathrm{b}$ and $=5 \mu \mathrm{m}$ in $\mathrm{d}$.

Fig. S3 Validation of the RNA-seq data by qRT-PCR. The ACTIN gene (Os11g0163100) was used as an endogenous reference for qPCR. Os01g0164600 (a), Os01g0289600 (b), Os02g0115700 (c), Os03g0319400 (d), and Os04g0610400(e) were selected for qPCR. The primer sequences were shown in Table S1.

Fig. S4 Cellular component GO terms significantly over-represented in DEGs GO enrichment analysis. a The DEGs-enriched GO terms at sampling point 22 of PR403. b The DEGs-enriched GO terms at sampling point 22 of PY6. c The DEGs-enriched GO terms at sampling point 20 of PR403. $\mathbf{d}$ The DEGs-enriched GO terms at sampling point 20 of PY6. 
Fig. S5 Molecular function GO terms significantly over-represented in DEGs GO enrichment analysis. a The DEGs-enriched GO terms at sampling point 22 of PR403. b The DEGs-enriched GO terms at sampling point 22 of PY6. c The DEGs-enriched GO terms at sampling point 20 of PR403. $\mathbf{d}$ The DEGs-enriched GO terms at sampling point 20 of PY6.

Fig. 66 Soft threshold power estimation in WGCNA analysis

Fig. S7 Scatter plot of module eigengenes in the modules significantly correlated with $\mathrm{H}_{2} \mathrm{O}_{2}$ and MDA. a $\mathrm{H}_{2} \mathrm{O}_{2}$ accumulation correlated Black, Blue, Green, and Grey60 modules. b MDA accumulation correlated Red, Brown, and Royalblue modules.

Fig. S8 GO terms over-represented in the GO enrichment analysis of hub genes in the modules that were correlated with $\mathrm{H}_{2} \mathrm{O}_{2}$ accumulation. The $\mathrm{GO}$ terms of biological processes, cellular components, and molecular functions were over-represented in a Black, b Blue, c Grey60, and d Green modules, respectively.

Fig. S9 $\mathrm{GO}$ terms over-represented in the $\mathrm{GO}$ enrichment analysis of hub genes in the modules that were correlated with MDA accumulation. The GO terms of biological processes, cellular components, and molecular functions were over-represented in a Red, b Brown, c Royalblue modules, respectively.

Fig. S10 Heatmap showing the expression patterns of the hub genes in the modules were correlated with $\mathrm{H}_{2} \mathrm{O}_{2}$ and MDA accumulation. a Black module. $\mathbf{b}$ Blue module. $\mathbf{c}$ Grey 60 module. $\mathbf{d}$ Green module. e Red. $\mathbf{f}$ Brown module. All the data used in the analysis was subjected to Log2 transformation.

Table S1 Primer sequences of genes using for qRT-PCR

Table S2 Candidate genes for $d s s-1$ in GWAS analysis

Table S3 Differentially expressed genes (DEGs) identified in RNA-seq

Table S4 Hub gene lists of the modules correlated with $\mathrm{H}_{2} \mathrm{O}_{2}$ and MDA accumulation

Table S5 Differentially expressed hub genes identified in Brown module

Table S6 GO enrichment analysis of DEGs and DEHGs identified in the study.

\section{Tables}

Table 1 The DEGs detected in PR403 and PY6 under drought stress treatment 


\begin{tabular}{cccc}
\hline Genotypes & Category of DEG & \multicolumn{2}{c}{ Sampling point } \\
\cline { 2 - 4 } & & $\mathbf{2 2}$ & $\mathbf{2 0}$ \\
\hline \multirow{3}{*}{ PR403 } & Up-regulated & 1135 & 2383 \\
\hline & Down-regulated & 1917 & 3438 \\
\hline \multirow{2}{*}{ PY6 } & Total & 3052 & 5821 \\
\hline \multirow{2}{*}{ Common } & Up-regulated & 1748 & 2655 \\
\hline & Down-regulated & 1397 & 2874 \\
\hline & Total & 3145 & 5529 \\
\hline & Up-regulated & 459 & 1202 \\
\cline { 2 - 4 } & Down-regulated & 683 & 1982 \\
\hline & Opposite-regulated & 477 & 532 \\
\hline & Total & 1619 & 3716 \\
\hline
\end{tabular}

Table 2 Differentially expressed hub genes identified in Grey 60 module 


\begin{tabular}{|c|c|c|c|c|c|c|}
\hline Gene_id & PR403_22 ${ }^{\mathrm{a}}$ & PR403_20 & PY6_22 & PY6_20 & Description & GO enrichment \\
\hline Os01G0842500 & $4.69^{c}$ & 4.40 & 5.85 & 8.49 & $\begin{array}{l}\text { Similar to Laccase (EC } \\
\text { 1.10.3.2). }\end{array}$ & $\begin{array}{l}\text { GO:0005507, } \\
\text { GO:0009809, } \\
\text { GO:0016722, } \\
\text { GO:0046274, } \\
\text { GO:0048046, } \\
\text { GO:0052716, } \\
\text { GO:0055114 }\end{array}$ \\
\hline Os03G0273200 & 4.65 & 3.70 & 6.79 & 9.00 & $\begin{array}{l}\text { Similar to Laccase (EC } \\
1.10 .3 .2 \text { ). }\end{array}$ & $\begin{array}{l}\text { GO:0005507, } \\
\text { GO:0009809, } \\
\text { GO:0016722, } \\
\text { GO:0046274, } \\
\text { GO:0048046, } \\
\text { GO:0052716, } \\
\text { GO:0055114 }\end{array}$ \\
\hline Os01G0702700 & 2.20 & 0.81 & 0.41 & 1.16 & $\begin{array}{l}\text { Similar to Transcription } \\
\text { factor MYB86 (Myb- } \\
\text { related protein 86) } \\
\text { (AtMYB86) (Myb } \\
\text { homolog 4) (AtMyb4). }\end{array}$ & GO:0003677 \\
\hline Os05G0543600 & 2.56 & 1.51 & 0.79 & 2.28 & $\begin{array}{l}\text { Similar to Myb-related } \\
\text { protein. }\end{array}$ & GO:0003677 \\
\hline Os04G0508500 & 3.65 & 3.34 & 0.50 & 1.18 & $\begin{array}{l}\text { MYB family } \\
\text { transcription factor, } \\
\text { putative, expressed. }\end{array}$ & GO:0003677 \\
\hline Os06G0131700 & 2.38 & 1.80 & 0.98 & 2.16 & Similar to NAM protein. & $\begin{array}{l}\text { GO:0003677, } \\
\text { GO:0005634, } \\
\text { GO:0006355 }\end{array}$ \\
\hline Os08G0189200 & 7.90 & 7.40 & 3.48 & 6.64 & $\begin{array}{l}\text { Germin-like protein } 8-3 \text {, } \\
\text { Disease resistance }\end{array}$ & $\begin{array}{l}\text { GO:0005618, } \\
\text { GO:0030145, } \\
\text { GO:0033609, } \\
\text { GO:0045735, } \\
\text { GO:0046564, } \\
\text { GO:0048046 }\end{array}$ \\
\hline Os03G0433200 & 3.04 & 2.62 & 1.94 & 2.63 & $\begin{array}{l}\text { SHR transcription } \\
\text { factor, Regulation of the } \\
\text { number of cortex cell } \\
\text { layers in the root, } \\
\text { Coordination of } \\
\text { stomatal patterning }\end{array}$ & $\begin{array}{l}\text { GO:0003700, } \\
\text { GO:0005634, } \\
\text { GO:0006355, } \\
\text { GO:0008356, } \\
\text { GO:0009956, } \\
\text { GO:0043565, } \\
\text { GO:0045930, } \\
\text { GO:0048366, } \\
\text { GO:0055072 }\end{array}$ \\
\hline
\end{tabular}

Notes: ${ }^{\mathrm{a}}$ represents the samples collected at the $22 \%$ of soil moisture content; ${ }^{\mathrm{b}}$ represents the samples collected at the $20 \%$ of soil moisture content; ${ }^{c}$ the value represents the Log 2 transformation of the fold change of the expression.

\section{Table 3 Differentially expressed hub genes identified in Red module}




\begin{tabular}{|c|c|c|c|c|c|c|}
\hline \multirow{2}{*}{ Gene_id } & PR403 & PR403 & PY6 & PY6 & Description & GO enrichment \\
\hline & $22^{\mathrm{a}}$ & $20^{\mathrm{b}}$ & 22 & 20 & & \\
\hline OS01G0730700 & $1.71^{\mathrm{c}}$ & -0.16 & 3.00 & 0.15 & $\begin{array}{l}\text { WRKY transcription } \\
\text { factor } 14 \text { (WRKY14). }\end{array}$ & $\begin{array}{l}\text { GO:0003700, GO:0006355, } \\
\text { GO:0043565 }\end{array}$ \\
\hline OS05G0474800 & 3.36 & 0.38 & 4.46 & 0.36 & $\begin{array}{l}\text { WRKY transcription } \\
\text { factor } 70 .\end{array}$ & $\begin{array}{l}\text { GO:0003700, GO:0006355, } \\
\text { GO:0043565 }\end{array}$ \\
\hline OS09G0417600 & 2.76 & -1.65 & 3.82 & 0.17 & $\begin{array}{l}\text { WRKY transcription } \\
\text { factor } 76 .\end{array}$ & $\begin{array}{l}\text { GO:0003700, GO:0006355, } \\
\text { GO:0009617, GO:0009620, } \\
\text { GO:0009751, GO:0010200, } \\
\text { GO:0043565 }\end{array}$ \\
\hline OS08G0386200 & 1.95 & -0.28 & 3.46 & 0.99 & $\begin{array}{l}\text { WRKY transcription } \\
\text { factor } 69 .\end{array}$ & $\begin{array}{l}\text { GO:0003700, GO:0006355, } \\
\text { GO:0043565 }\end{array}$ \\
\hline OS01G0185900 & 0.19 & -3.15 & 2.43 & -2.67 & $\begin{array}{l}\text { Similar to WRKY } 1 \\
\text { (Fragment). }\end{array}$ & $\begin{array}{l}\text { GO:0003700, GO:0006355, } \\
\text { GO:0043565 }\end{array}$ \\
\hline OS05G0322900 & 1.25 & -1.98 & 3.04 & -0.17 & $\begin{array}{l}\text { Similar to WRKY } \\
\text { transcription factor } 45 \text {. }\end{array}$ & $\begin{array}{l}\text { GO:0003700, GO:0009862, } \\
\text { GO:0009864, GO:0010200, } \\
\text { GO:0043565, GO:0045892, } \\
\text { GO:0050832, GO:1900056 }\end{array}$ \\
\hline OS05G0571200 & 3.60 & -0.37 & 5.70 & 2.53 & $\begin{array}{l}\text { Similar to WRKY } \\
\text { transcription factor } 19 .\end{array}$ & $\begin{array}{l}\text { GO:0003700, GO:0006355, } \\
\text { GO:0043565 }\end{array}$ \\
\hline OS11G0117600 & 3.59 & -0.18 & 5.29 & 3.60 & $\begin{array}{l}\text { Similar to WRKY } \\
\text { transcription factor } 50 \\
\text { (Fragment). }\end{array}$ & $\begin{array}{l}\text { GO:0003700, GO:0006355, } \\
\text { GO:0043565 }\end{array}$ \\
\hline OS03G0437200 & 1.00 & -1.14 & 5.03 & 0.67 & $\begin{array}{l}\text { C2H2-type zinc finger } \\
\text { protein, Abscisic acid- } \\
\text { induced antioxidant } \\
\text { defence, Water stress and } \\
\text { oxidative stress tolerance }\end{array}$ & $\begin{array}{l}\text { GO:0003700, GO:0005634, } \\
\text { GO:0006355, GO:0043565, } \\
\text { GO:0044212, GO:0046872 }\end{array}$ \\
\hline OS10G0377300 & 5.42 & 0.66 & 3.21 & -4.34 & $\begin{array}{l}\text { Similar to Homeobox- } \\
\text { leucine zipper protein } \\
\text { HOX8. }\end{array}$ & $\begin{array}{l}\text { GO:0003700, GO:0005634, } \\
\text { GO:0006355, GO:0043565 }\end{array}$ \\
\hline OS12G0555200 & 3.14 & 1.10 & 6.30 & 3.50 & $\begin{array}{l}\text { Similar to Probenazole- } \\
\text { inducible protein PBZ1. }\end{array}$ & $\begin{array}{l}\text { GO:0004864, GO:0004872, } \\
\text { GO:0005634, GO:0005737, } \\
\text { GO:0006952, GO:0009607, } \\
\text { GO:0009738, GO:0010427, } \\
\text { GO:0043086, GO:0080163 }\end{array}$ \\
\hline OS12G0555500 & 2.03 & 0.42 & 4.62 & 2.85 & $\begin{array}{l}\text { Pathogen resistance } \\
\text { protein } \mathrm{PBZ1,C} 17 \mathrm{kDa} \\
\text { RNase, Disease } \\
\text { resistance }\end{array}$ & $\begin{array}{l}\text { GO:0004864, GO:0004872, } \\
\text { GO:0005634, GO:0005737, } \\
\text { GO:0006952, GO:0009607, } \\
\text { GO:0009738, GO:0010427, } \\
\text { GO:0043086, GO:0080163 }\end{array}$ \\
\hline OS12G0555000 & 3.75 & 0.52 & 6.81 & 4.27 & $\begin{array}{l}\text { Similar to Probenazole- } \\
\text { inducible protein PBZ1. }\end{array}$ & $\begin{array}{l}\text { GO:0004864, GO:0004872, } \\
\text { GO:0005634, GO:000573, } \\
\text { GO:0009738, GO:0010427, } \\
\text { GO:0043086, GO:0080163 }\end{array}$ \\
\hline OS12G0555300 & 3.35 & 0.35 & 5.23 & 2.70 & $\begin{array}{l}\text { Similar to Pathogenesis- } \\
\text { related protein PR-10a. }\end{array}$ & GO:0006952, GO:0009607 \\
\hline OS02G0282000 & 3.52 & 1.30 & 4.64 & 2.65 & $\begin{array}{l}\text { NB-ARC domain } \\
\text { containing protein. }\end{array}$ & GO:0043531 \\
\hline OS01G0134700 & 2.02 & -0.96 & 3.78 & 0.29 & $\begin{array}{l}\text { Calmodulin binding } \\
\text { protein-like family } \\
\text { protein. }\end{array}$ & $\begin{array}{l}\text { GO:0002229, GO:0003700, } \\
\text { GO:0005516, GO:0005634, } \\
\text { GO:0006355, GO:0010112, } \\
\text { GO:0010224, GO:0043565, } \\
\text { GO:0071219, GO:0080142, } \\
\text { GO:1900426 }\end{array}$ \\
\hline OS01G0508100 & 2.48 & -1.35 & 4.13 & 0.89 & $\begin{array}{l}\text { Ferritin/ribonucleotide } \\
\text { reductase-like family } \\
\text { protein. }\end{array}$ & GO:0010112 \\
\hline
\end{tabular}




\section{Table 3 Differentially expressed hub genes identified in Red module (continued)}

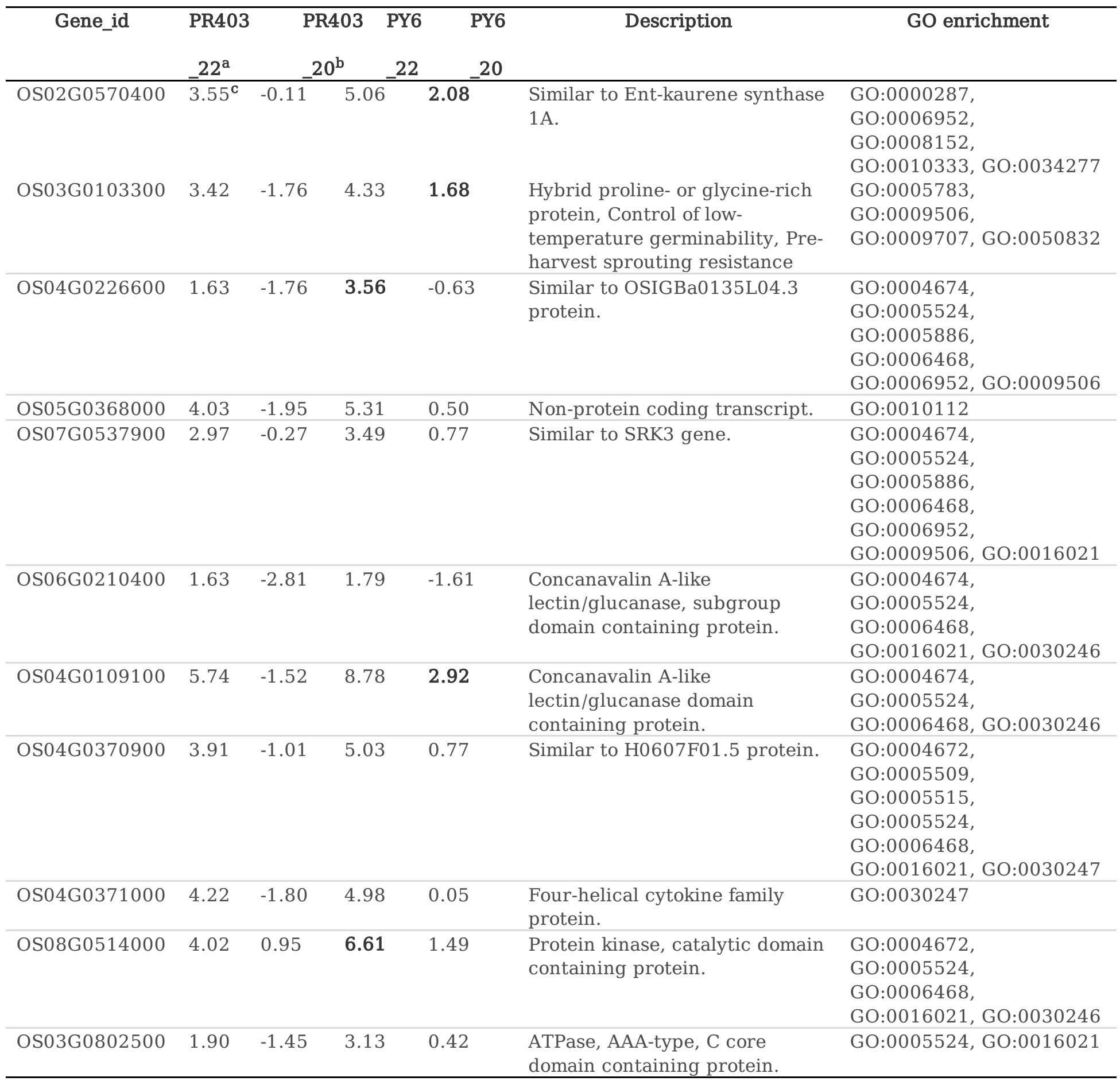


Notes: ${ }^{\mathrm{a}}$ represents the samples collected at the $22 \%$ of soil moisture content; ${ }^{\mathrm{b}}$ represents the samples collected at the $20 \%$ of soil moisture content; ${ }^{c}$ the value represents the Log 2 transformation of the fold change of the expression.

Table 4 Differentially expressed hub genes identified in Royalblue module

\begin{tabular}{|c|c|c|c|c|c|c|}
\hline Gene_id & $\begin{array}{c}\text { PR403 } \\
22^{\mathrm{a}}\end{array}$ & $\begin{array}{c}\text { PR403 } \\
20^{\mathrm{b}}\end{array}$ & $\begin{array}{l}\text { PY6 } \\
22\end{array}$ & $\begin{array}{r}\text { PY6 } \\
20\end{array}$ & Description & GO enrichment \\
\hline Os01g0298400 & $1.91^{\mathrm{c}}$ & -0.31 & 3.15 & 0.57 & $\begin{array}{l}\text { Myb } \\
\text { transcription } \\
\text { factor domain } \\
\text { containing } \\
\text { protein. }\end{array}$ & GO:0003677 \\
\hline Os01g0392600 & -0.81 & -2.14 & 2.14 & -2.02 & $\begin{array}{l}\text { Conserved } \\
\text { hypothetical } \\
\text { protein. }\end{array}$ & \\
\hline Os03g0663600 & 1.87 & 0.68 & 4.31 & 2.03 & $\begin{array}{l}\text { Similar to } \\
\text { Pathogenesis- } \\
\text { related } \\
\text { thaumatin-like } \\
\text { protein. }\end{array}$ & \\
\hline Os12g0630200 & 0.44 & -2.47 & 2.76 & -0.64 & $\begin{array}{l}\text { Thaumatin\%2C } \\
\text { pathogenesis- } \\
\text { related family } \\
\text { protein. }\end{array}$ & \\
\hline Os11g0592200 & 0.33 & -2.22 & 2.14 & -1.30 & $\begin{array}{l}\text { Similar to Chitin- } \\
\text { binding allergen } \\
\text { Bra r } 2 \\
\text { (Fragments). }\end{array}$ & GO:0042742, GO:0050832 \\
\hline Os04g0494100 & 1.63 & 0.65 & 4.83 & 1.19 & $\begin{array}{l}\text { Similar to } \\
\text { Chitinase. }\end{array}$ & $\begin{array}{l}\text { GO:0000272, GO:0004568, GO:0005618, } \\
\text { GO:0006032, GO:0006952, GO:0008061, } \\
\text { GO:0009611, GO:0009617, GO:0010262, } \\
\text { GO:0016998 }\end{array}$ \\
\hline Os06g0487620 & 1.97 & 1.70 & 2.31 & 0.98 & $\begin{array}{l}\text { Conserved } \\
\text { hypothetical } \\
\text { protein. }\end{array}$ & \\
\hline Os06g0493100 & 5.99 & 0.26 & 5.93 & 1.68 & $\begin{array}{l}\text { Conserved } \\
\text { hypothetical } \\
\text { protein. }\end{array}$ & GO:0016021 \\
\hline Os06g0586300 & -0.01 & 1.13 & 5.08 & 3.48 & $\begin{array}{l}\text { Hypothetical } \\
\text { protein. }\end{array}$ & \\
\hline Os06g0588450 & -1.00 & -1.82 & 4.64 & 2.74 & $\begin{array}{l}\text { Hypothetical } \\
\text { conserved gene. }\end{array}$ & \\
\hline Os06g0591200 & 4.28 & -2.17 & 8.51 & 4.08 & $\begin{array}{l}\text { Conserved } \\
\text { hypothetical } \\
\text { protein. }\end{array}$ & \\
\hline
\end{tabular}

Notes: ${ }^{\mathrm{a}}$ represents the samples collected at the $22 \%$ of soil moisture content; ${ }^{\mathrm{b}}$ represents the samples collected at the $20 \%$ of soil moisture content; ${ }^{\mathrm{c}}$ the value represents the $\log 2$ transformation of the fold change of the expression.

Figures 

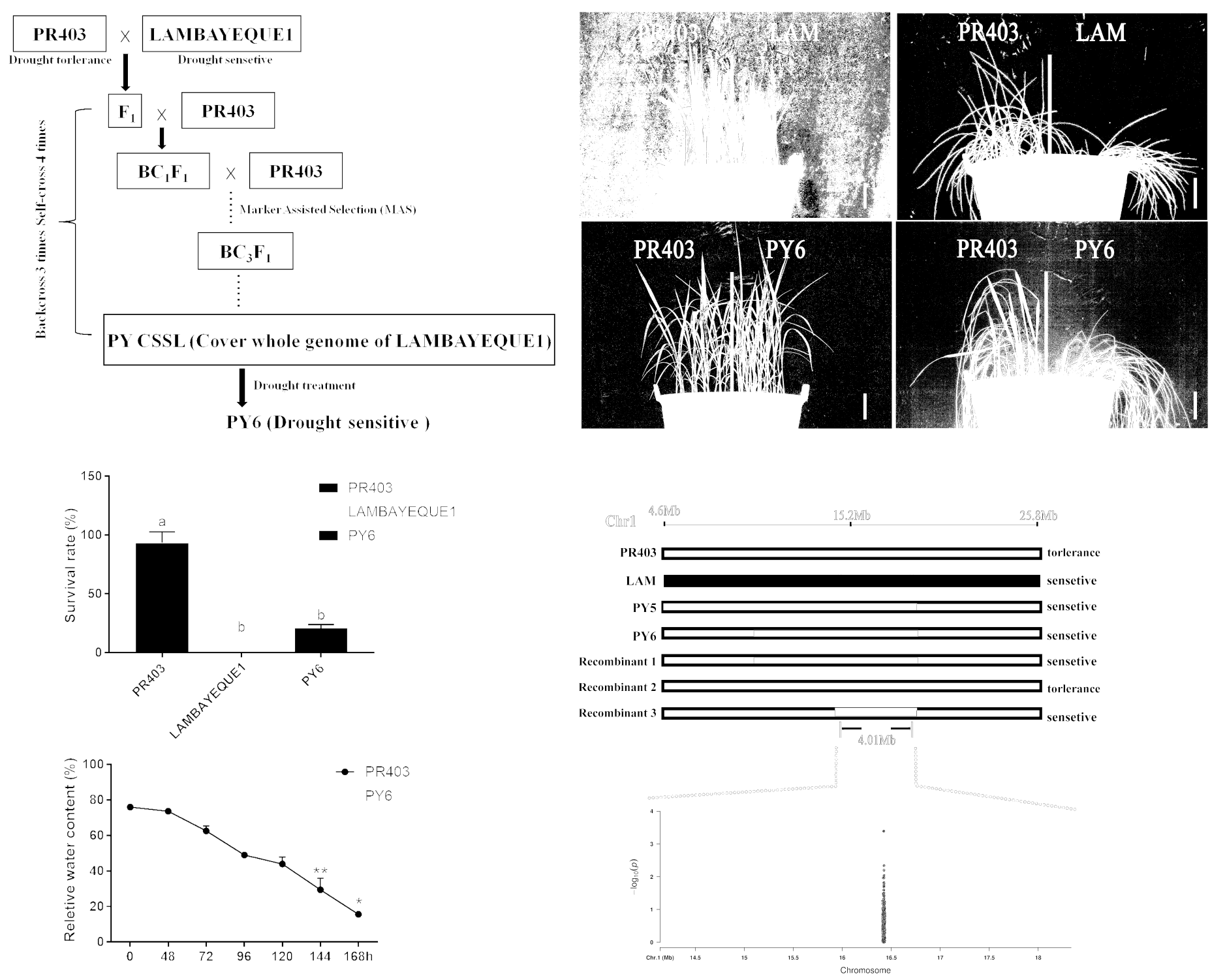

\section{Figure 1}

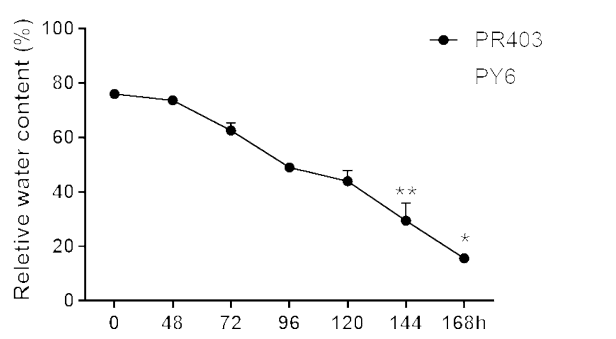

Characterization of a drought sensitive CSSL. a Flowchart of the CSSL construction and drought sensitive CSSL identification. b Drought stress phenotype of PR403, LAMBAYEQUE1, and PY6. c Survival rate of PR403, LAMBAYEQUE1, and PY6 after the drought stress treatment. Data are presented as mean \pm $S D\left(n=3,{ }^{*}<0.05,{ }^{*} P<0.01\right.$, Student's $t$ test). $d$ Relative water content of leaves of PR403 and PY6 under drought stress treatment. ( $n=3,{ }^{*} P<0.05,{ }^{*} P<0.01$, Student's $t$ test). e Fine mapping and GWAS analysis of QTL dss-1 underlying drought sensitive phenotype of PY6. Scale bar $=5 \mathrm{~cm}$ in b. 


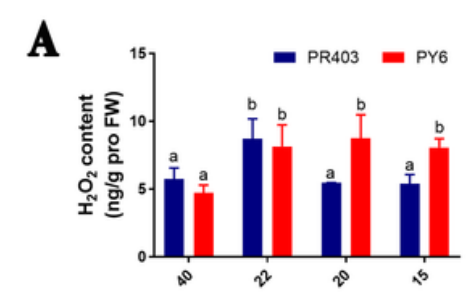

D

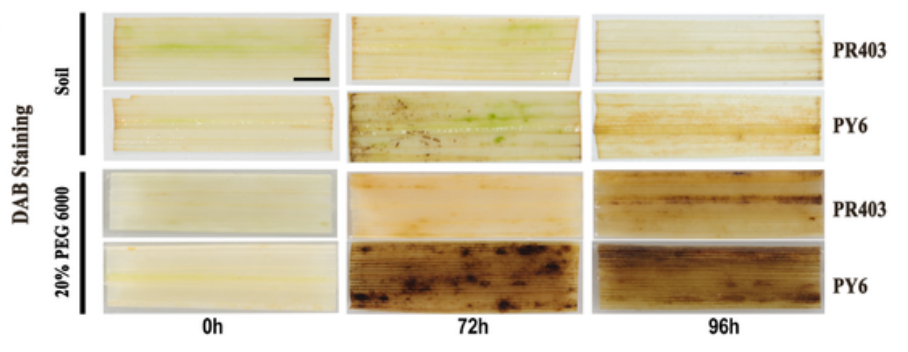

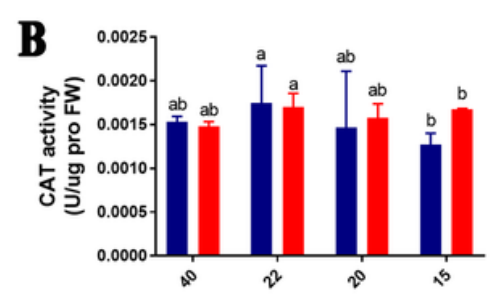

R403

$\mathbf{E}$
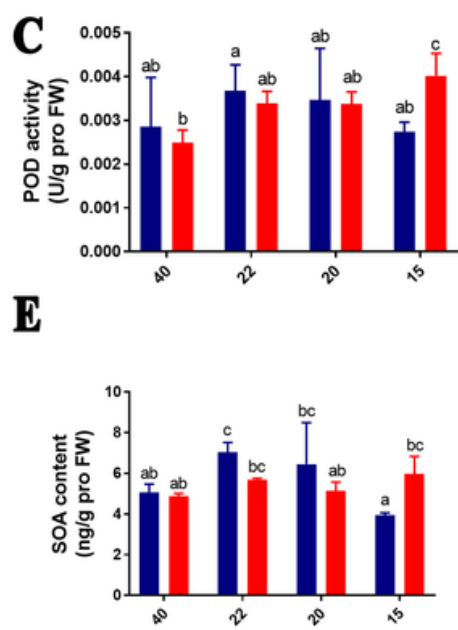
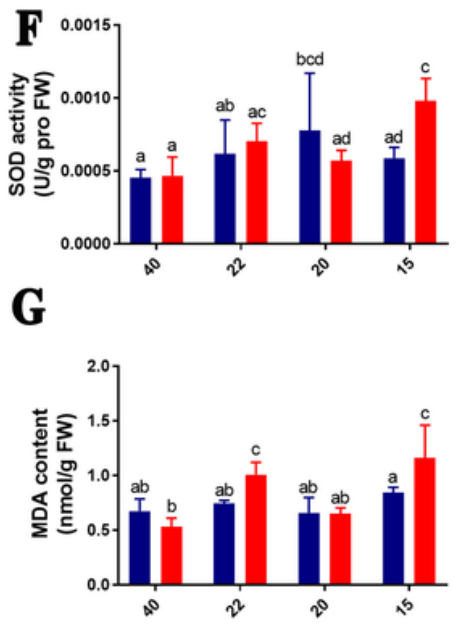

Figure 2

Comparison of ROS production and elimination in PY6 and PR403 under drought stress treatment. a H2O2 content. b CAT activity. c POD activity. d DAB staining of leaf samples of PY6 and PR403. e SOA content. $f$ SOD activity. $g$ The content of MDA. Data are presented as mean $\pm S D(n=3, * P<0.05, \star \star P<$ 0.01 , Student's t test). Scale bar $=0.5 \mathrm{~cm}$ in $\mathrm{d}$.

$\mathbf{A}$

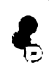

B

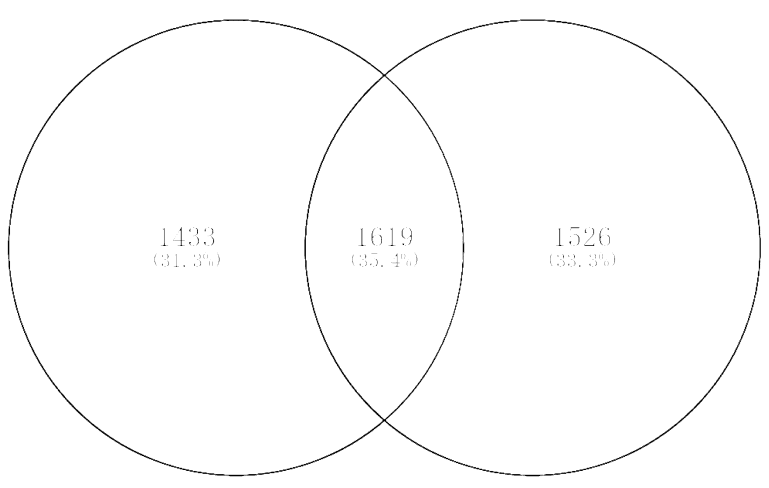

C

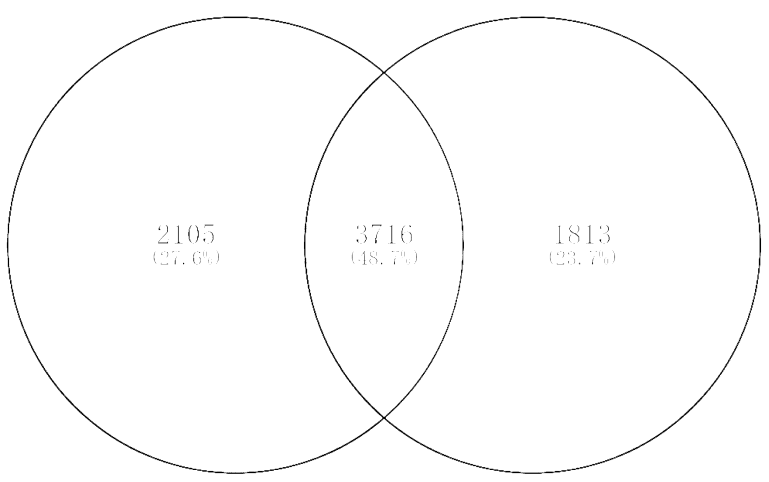




\section{Figure 3}

Global view of gene expression profiling under drought treatment. a Principal component analysis (PCA) of the RNA-Seq data. b-c Venn diagrams showing the number of DEGs identified at two sampling points of PR403 and PY6. $\mid \log 2 \mathrm{FCl} \geq 1$, padj $<0.05$ was used as threshold for DEGs identification.

A

Go enrichment of BP

-

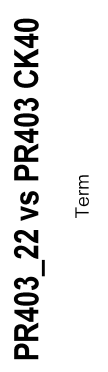

C

Enrichment score

Go enrichment of BP

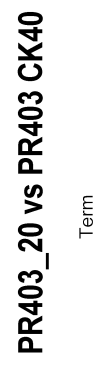

B

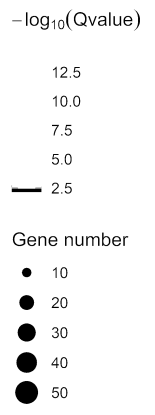

D
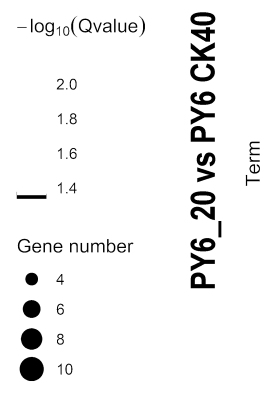

Go enrichment of BP

Gene number

- 10

- 15

25

$-\log _{10}$ (Qvalue)

10

8

6

Go enrichment of BP

Gene number

- 3

- 6

9

12

15

$-\log _{10}$ (Qvalue)

3.5

3.0

2.5

2.0
$-\quad 1.5$

Enrichment score

Enrichment score

\section{Figure 4}

Top 20 of biological process $\mathrm{GO}$ terms significantly over-represented in DEGs GO enrichment analysis. a The DEGs-enriched GO terms at sampling point 22 of PR403. b The DEGs-enriched GO terms at sampling point 22 of PY6. c The DEGs-enriched GO terms at sampling point 20 of PR403. d The DEGs-enriched GO terms at sampling point 20 of PY6. 
A

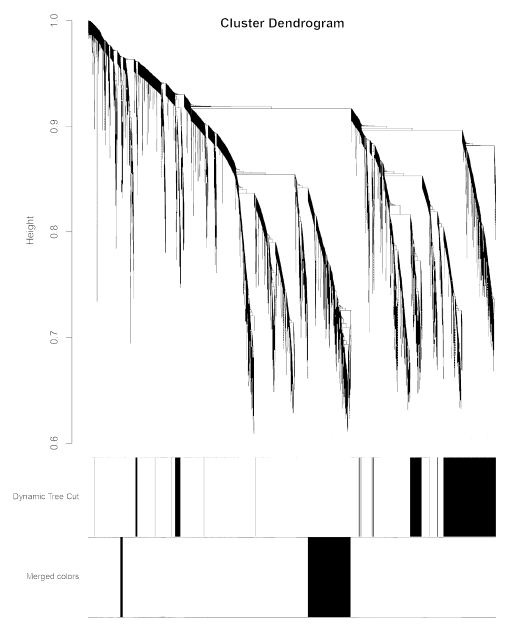

B

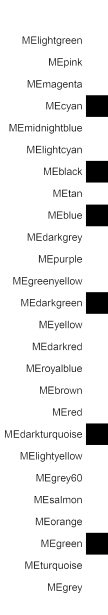

C

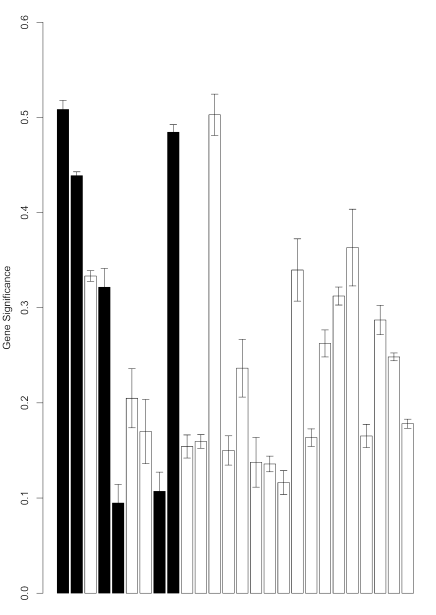

D

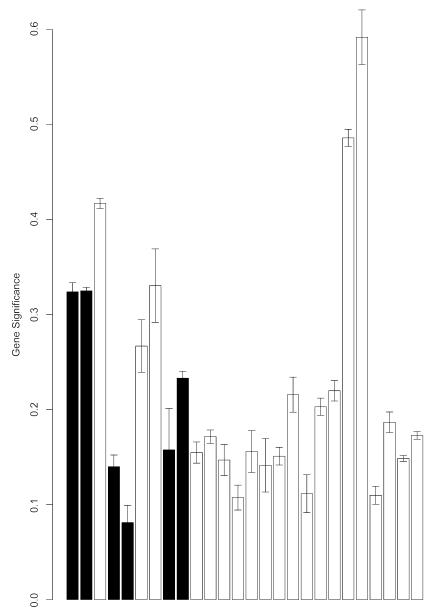

Figure 5

WGCNA co-expression network and module-trait correlation analysis. a A hierarchical cluster tree showing co-expression modules identified via the Dynamic Tree Cut method. Each leaf in the tree represents one gene. The major tree branches constitute 26 modules and are labeled with different colors. $b$ The correlation of physiological indicators with WGCNA modules. Each row corresponds to a module and labeled with a color as in a; The columns correspond to physiological indicators. The color of each cell indicates the correlation coefficient between the module and physiological indicator (the top number in the cell represent correlation coefficient and bottom one in the parentheses represent $P$ value). $c$ Correlation of $\mathrm{H} 2 \mathrm{O} 2$ with WGCNA modules. Color bars with the numbers in X-axis correspond to the module colors and the numbers showed in b. d Correlation of $\mathrm{H} 2 \mathrm{O} 2$ with WGCNA modules. Color bars with the numbers in X-axis correspond to the module colors and the numbers showed in $\mathrm{b}$.

A

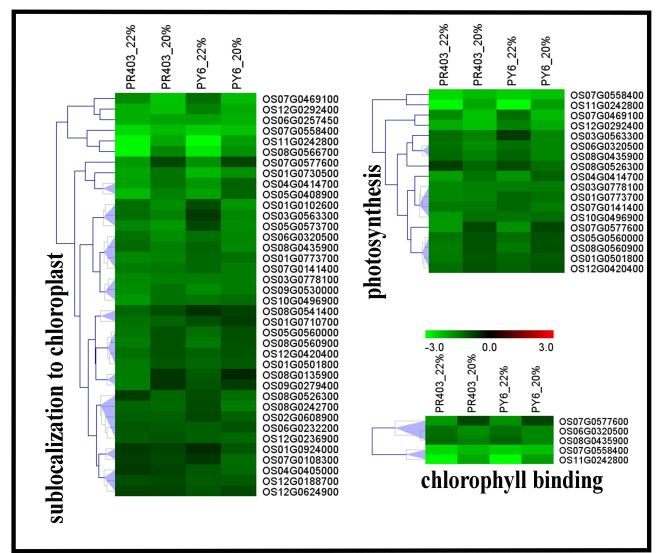

Black module
B

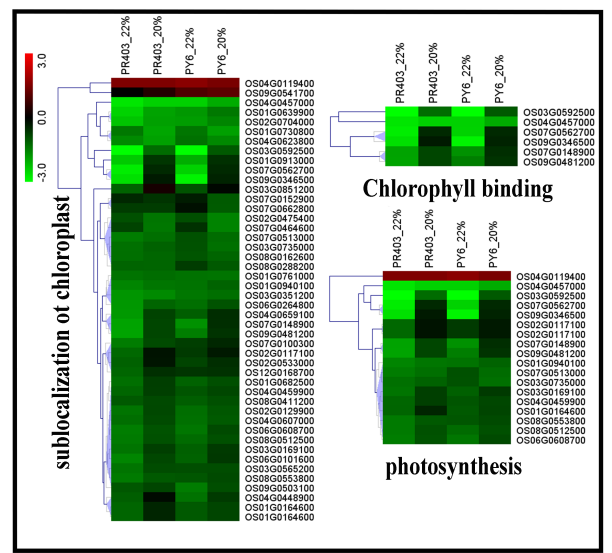

Blue module
C

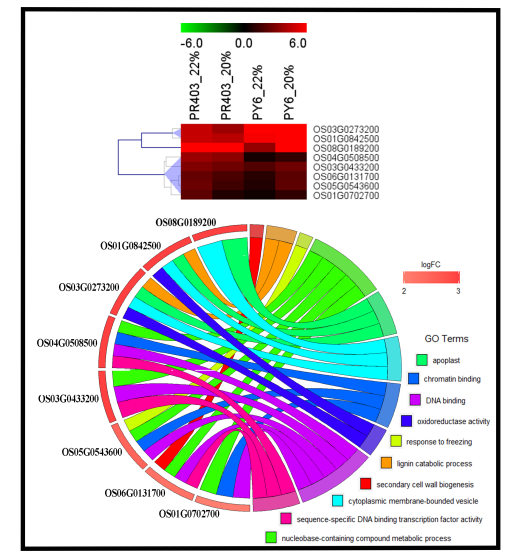

Grey 60 module

Figure 6 
Heatmap and circular plot showing the expression alterations and functional annotations of hub genes in the modules that were correlated with $\mathrm{H} 2 \mathrm{O} 2$ accumulation. a-b The expression patterns of hub genes of black and blue modules showing they were related to photosynthesis of rice plants. $c$ The expression patterns and GO enrichment of hub genes of Grey60 module. All the data used in the analysis was subjected to Log2 transformation.
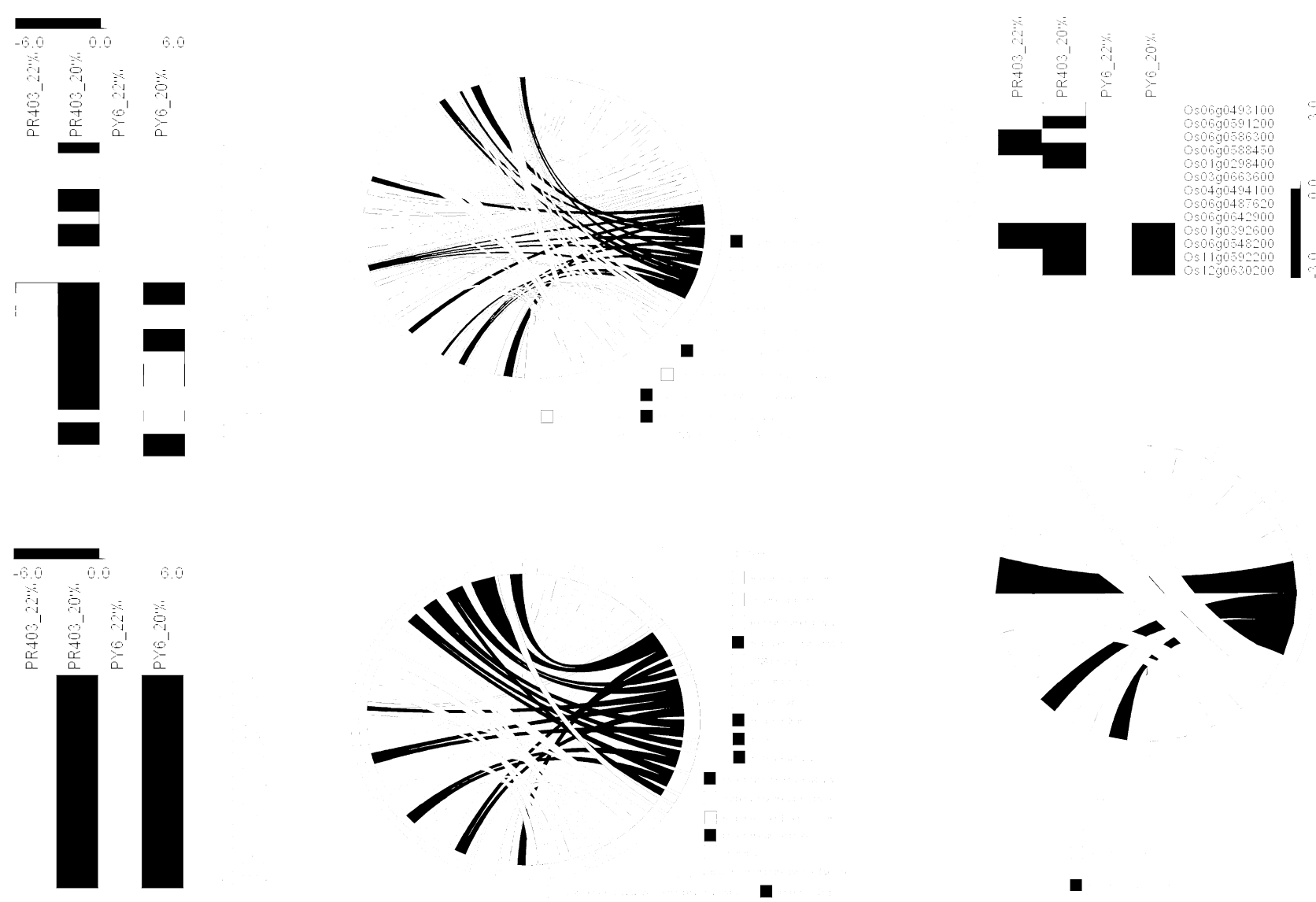

\section{Figure 7}

Heat map and circular plot showing the expression alterations and functional annotations of hub genes in the modules that were correlated with MDA accumulation. a The expression patterns and GO enrichment of hub genes of Red module. $b$ The expression patterns and $G O$ enrichment of hub genes of Brown module. c The expression patterns and GO enrichment of hub genes of Royalblue module. All the data used in the analysis was subjected to Log2 transformation. 


\section{$\mathbf{H}_{2} \mathbf{O}_{2}$}

\section{MDA}

\section{Figure 8}

The possible role of dss- 1 in reprogramming the transcriptional profiles of rice in response to drought stress.

\section{Supplementary Files}

This is a list of supplementary files associated with this preprint. Click to download.

- Fig.S1.tif

- Tables1.xlsx

- Tables5.rtf 
- TableS2.docx

- TableS3.xIsx

- Fig.S21.tif

- Tables4.xIsx

- Fig.S31.tif

- Fig.S41.tif

- Tables6.xIsx

- Fig.S51.tif

- Fig.S6.tif

- Fig.S71.tif

- Fig.S81.tif

- Fig.S91.tif

- Fig.S101.tif 